\title{
Synthesis, antibacterial and antioxidant evaluation of 4-substituted 1-(4-methoxyphenyl)pyrrolidin-2-ones
}

\author{
K. Anusevičius, E. Slaninaitė, I. Jonuškienė, B. Sapijanskaitė, \\ R. Vaickelionienė, V. Mickevičius
}

\author{
Kaunas University of Technology \\ Radvilenu st. 19, LT-50270 Kaunas, Lithuania \\ E-mail:vytautas.mickevicius@ktu.lt \\ cross $^{\text {ref }}$ http://dx.doi.org/10.5755/j01.ct.65.1.8881
}

Received 28 November 2014; Accepted 15 December 2014

\begin{abstract}
4-Substituted 1-(4-methoxyphenyl)pyrrolidin-2-ones containing azole, diazole, oxadiazole, thiadiazole, and triazole fragments have been synthesized, and the characterization of the obtained products is presented. The study compounds have been analyzed for antioxidant and antibacterial activities. Two types of hetero systems - 5-thioxo-4,5-dihydro-1,3,4-oxadiazole and $[1,2,4]$ triazolo[3,4- $b][1,3,4]$ thiadiazine - showed a moderate activity against Rhizobium radiobacter, Xanthomonas campestris, and Escherichia coli microorganisms. Some compounds were tested for their antioxidant activity.
\end{abstract}

Keywords: 1,4-disubstituted pyrrolidin-2-ones, azoles, antibacterial, antioxidant activities.

\section{Introduction}

Among azoles, many biologically active compounds are known. Synthetic azole derivatives possess antituberculous [1], antifungal [2-4], and antimicrobial [5-7] activity. They also may be used as crop protectors $[8,9]$. The 1,3,4-oxadiazole compounds often display antifungal, herbicidal [10], and insecticidal [11, 12] effects. 1,2,4-Triazoles have attracted particular attention due to the wide range of their biological properties such as antibacterial and antifungal [13-16], anticancerantitumour [17], antidepressant [18]. Strains of the Rhizobium species (formerly Agrobacterium, which was reclassified based on $16 \mathrm{~S}$ rDNA analyses) are aerobic, motile, oxidase-positive, and non-spore-forming gramnegative bacilli. Among the species of Rhizobium (i. e. $R$. radiobacter, R. rhizogenes, $R$. rubi, $R$. undicola, and $R$. vitis), $R$. radiobacter is the species that most commonly causes disease in humans. Since the first case of human infection with $R$. radiobacter in a patient with prosthetic aortic valve endocarditis was reported in 1980, $R$. radiobacter has been recognized as an opportunistic human pathogen. Most of patients with $R$. radiobacter infection have debilitating underlying diseases [19]. Bacteria belonging to the genus Xanthomonas are one of the most omnipresent groups of Gram-negative plant pathogenic bacteria and cause a variety of diseases in multiple plants [20]. Xanthomonas campestris pv. campestris (Xcc), the cause of black rot of crucifers, is a seed-borne bacterium which occurs worldwide [21]. Antioxidants are extensively studied for their capacity to protect an organism and cell from damage induced by oxidative stress. Scientists in many different disciplines have become more interested in new compounds, either synthesized or obtained from natural sources that could provide active components to prevent or reduce the impact of oxidative stress on a cell [22].

As a continuation of our interest in the synthesis and application of new azole derivatives [23-25] the title compounds with $\mathrm{O}, \mathrm{S}$, and $\mathrm{N}$ heteroatoms were synthesized.

\section{Results and discussion}

\section{Chemistry}

The pathway of synthesis of the new 1,4disubstituted pyrrolidinones is shown in Scheme 1 (2-13) and Scheme 2 (14-23).

In this work, functionalized pyrrole and pyrazole derivatives 2,3 were prepared by refluxing a mixture of the carbohydrazide 1 with diketones -2,5-hexanedione or 2,4-pentanedione in 2-propanol in the presence of the catalytic amount of hydrochloric or acetic acids. The obtained products were identified from the characteristic proton resonances of two $\mathrm{CH}_{3}$ groups of the pyrrole ring at $2.00 \mathrm{ppm}$ and signal at $5.66 \mathrm{ppm}$, attributed to the $\mathrm{CH}$ groups of compound 2, whereas, the ones at $2.19 \mathrm{ppm}$, $2.48 \mathrm{ppm}\left(\mathrm{CH}_{3}\right.$ groups), and $6.11 \mathrm{ppm}(\mathrm{CH}$ group) in the ${ }^{1} \mathrm{H}$ NMR spectrum of compound $\mathbf{3}$ confirmed the formation of a pyrazole ring. Refluxing of hydrazide $\mathbf{1}$ in the excess of triethyl orthoformate, in the presence of $p$ toluenesulfonic acid for 20 hours, gave 2-substituted oxadiazole 5, and the shortening of the reaction time to about 1 minute allowed us to isolate the hydrazone-type intermediate 4. The NMR spectra of compound 4 exhibit four sets of resonances; therefore, four different spatial states may exist in the DMSO- $d_{6}$ solution. $\mathrm{N}$-Phenylhydrazinecarboxamide $\mathbf{6}$ and $\mathrm{N}$ phenylhydrazinecarbothioamide 7 were synthesized by 
the interaction of the hydrazide $\mathbf{1}$ with phenyliso- and phenylisothiocianates in methanol. These compounds were used for the synthesis of heterocycles 8-11. It was found that intramolecular heterocyclization of thiosemicarbazide $\mathbf{7}$ in acidic conditions led to the formation of 1,3,4-thiadiazole $\mathbf{8}$, while under the basic conditions 1,2,4-triazoles $\mathbf{1 0}$ and $\mathbf{1 1}$ were obtained from compounds $\mathbf{6}, 7$. The conversion of semicarbazides $\mathbf{5 , 6}$ was carried out by refluxing them in a $2 \%$ aqueous $\mathrm{NaOH}$ solution with the subsequent acidification of the reaction mixture with acetic acid. The singlets at 11.87 ppm and $13.86 \mathrm{ppm}$ have been ascribed to protons of the $\mathrm{NH}$ groups of 1,2,4-triazoles 10, 11 in the ${ }^{1} \mathrm{H} \mathrm{NMR}$ spectra. The resonances at $147.3 \mathrm{ppm}$ and $152.8 \mathrm{ppm}$ have been assigned to $\mathrm{C}=\mathrm{N}$, and the ones at $155.9 \mathrm{ppm}$ and $170.5 \mathrm{ppm}$ have been attributed to $\mathrm{C}=\mathrm{O}$ and $\mathrm{C}=\mathrm{S}$ carbon atoms, respectively, of the 5-membered heterocycle moiety of compounds $\mathbf{1 0}, 11$ in ${ }^{13} \mathrm{C} \mathrm{NMR}$ spectra.

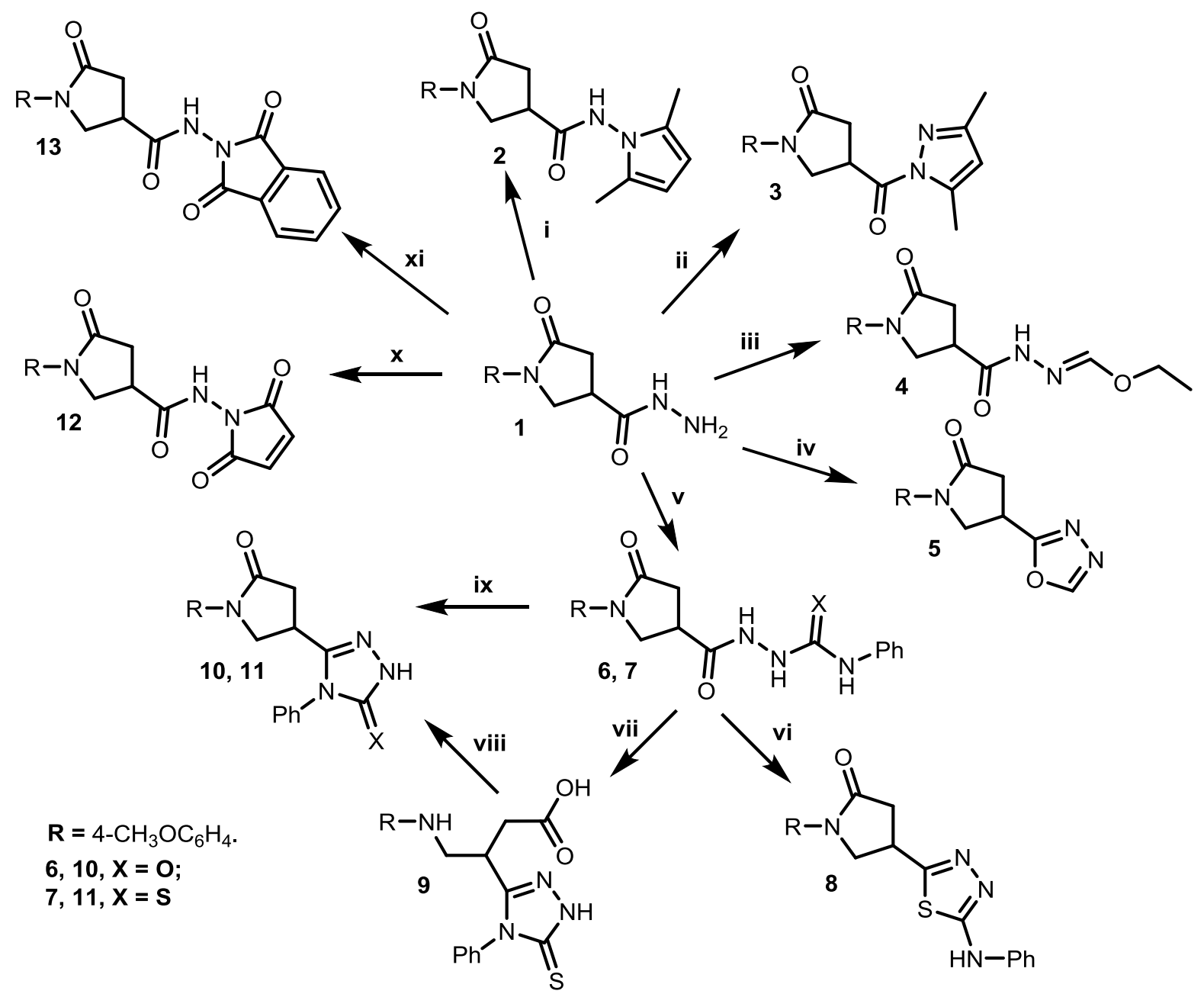

Reagents and conditions: i: 2,5-Hexanedione, $\mathrm{CH}_{3} \mathrm{COOH}, 2-\mathrm{PrOH}, \Delta, 3 \mathrm{~h}$; ii: 2,4-Pentanedione, $\mathrm{HCl}, 2-\mathrm{PrOH}$, $\Delta, 2 \mathrm{~h}$; iii: Ethyl orthoformate, heated to boiling; iv: Ethyl orthoformate, p-toluenesulfonic acid, $\Delta, 20 \mathrm{~h}$; v: $\mathrm{PhNCO}, \mathrm{MeOH}$, r.t., $2 \mathrm{~h}$; $\mathrm{PhNCS}, \mathrm{MeOH}, \Delta, 1 \mathrm{~h}$; vi: $\mathrm{H}_{2} \mathrm{SO}_{4}$, r.t., stirred $1 \mathrm{~h}, 2 \% \mathrm{Na}_{2} \mathrm{CO}_{3}, \mathrm{pH} \mathrm{10}$; vii: $20 \% \mathrm{NaOH}, \Delta, 3 \mathrm{~h}, \mathrm{CH}_{3} \mathrm{COOH}, \mathrm{pH}$; viii: $10 \% \mathrm{HCl}$, heated to boiling; ix: $2 \% \mathrm{NaOH}, \Delta, 3 \mathrm{~h}, 10 \% \mathrm{HCl}$, $\mathrm{pH}$ 2; $\mathbf{x}$ : Maleic anhydride, 1,4-dioxane, $\Delta, 3 \mathrm{~h}$; xi: Phthalic anhydride, $\mathrm{CH}_{3} \mathrm{COOH}, \Delta, 24 \mathrm{~h}, \mathrm{H}_{2} \mathrm{O}$

Scheme 1. Synthesis of azoles 2-13

4-[(4-Methoxyphenyl)amino]-3-(4-phenyl-5-thioxo4,5-dihydro-1 $H$-1,2,4-triazol-3-yl)butanoic acid (9) was synthesized from thiosemicarbazide 7 by cleaving the pyrrolidinone ring with a $20 \% \mathrm{NaOH}$ solution under reflux. The same triazole cycle formation took place. Heating this compound in a $10 \%$ HCI solution lead to the formation of triazole 11. The proton resonance of the $\mathrm{NH}$ group at $5.48 \mathrm{ppm}$ in ${ }^{1} \mathrm{H}$ NMR spectrum confirmed the existence of an open chain in compound $\mathbf{9}$. Compounds 12, 13 with dioxodihydropyrrolylic fragments were synthesized from hydrazide $\mathbf{1}$ and maleic or phthalic anhydride respectively. The reactions were carried out at reflux in 1,4-dioxane or acetic acid.

One of the ways to obtain oxadiazole and triazole heterosystems is their synthesis from dithiocarbazates. For the synthesis of oxadiazole and triazole derivatives, hydrazide 1 was heated with carbon disulfide in methanol in the presence of potassium hydroxide. Upon refluxing, the formed potassium dithiocarbazate $\mathbf{1 4}$ was dissolved in water, and subsequent acidification of the reaction 
mixture with diluted hydrochloric acid to $\mathrm{pH} 1$ gave 1 -(4methoxyphenyl)-4-(4,5-dihydro-5-thioxo-1,3,4-

oxadiazol-2-yl)pyrrolidin-2-one (15). The formation of the oxadiazolethione ring in compound $\mathbf{1 5}$ has been proven by the signals at $163.9 \mathrm{ppm}(\mathrm{O}-\mathrm{C}=\mathrm{N})$ and 177.9 ppm $(\mathrm{C}=\mathrm{S})$ in ${ }^{13} \mathrm{C}$ NMR spectrum and by the broad singlet at $14.78 \mathrm{ppm}(\mathrm{NH})$ in ${ }^{1} \mathrm{H}$ NMR spectrum. A characteristic absorption band of the $\mathrm{NH}$ group of compound 15 was observed at $3056 \mathrm{~cm}^{-1}$ in the IR spectrum. The absorption bands at $1658 \mathrm{~cm}^{-1}$ and 1248 $\mathrm{cm}^{-1}$ have been ascribed to the $\mathrm{C}=\mathrm{O}$ group of the pyrrolidinone ring and the $\mathrm{C}=\mathrm{S}$ group of the oxadiazole cycle, respectively.<smiles>[R]N1C[C@H](C(=O)NN)CC(=O)N1[R]</smiles><smiles>[Y]CCC(C)C[R]</smiles>

20<smiles>[Y17][14CH2]C=Nn1c([C@@H]2CC(=O)N([R])C2)n[nH]c1=S</smiles>

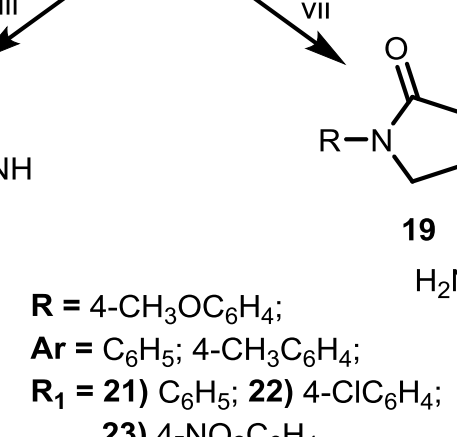

Reagents and conditions: i: $\mathrm{KOH}, \mathrm{CS}_{2}, \mathrm{MeOH}, \Delta, 24 \mathrm{~h}$; ii: $10 \% \mathrm{HCl}, \mathrm{pH}$; iii: $\mathrm{N}_{2} \mathrm{H}_{4}, \mathrm{H}_{2} \mathrm{O}, \Delta, 8 \mathrm{~h}$, $\mathrm{CH}_{3} \mathrm{COOH}, \mathrm{pH}$ 7; iv: $10 \% \mathrm{HCl}, \mathrm{pH}$ 1; v: $\mathrm{N}_{2} \mathrm{H}_{4} \cdot \mathrm{H}_{2} \mathrm{O}, \mathrm{H}_{2} \mathrm{O}, \Delta, 24 \mathrm{~h}, \mathrm{CH}_{3} \mathrm{COOH}, \mathrm{pH}$ 6; vi: ArCHO 2-PrOH, $\mathrm{HCl}, \Delta, 8 \mathrm{~h}$; vii: Ethyl chloroacetate, triethylamine, 2-PrOH, $\Delta, 7 \mathrm{~h}$; viii: 2,5-Hexanedione, $\mathrm{HCl}, \mathrm{EtOH}, \Delta$, $7 \mathrm{~h}$; ix: $\alpha$-Haloketone, triethylamine, $\mathrm{MeOH}, \Delta, 4 \mathrm{~h}$

Scheme 2. Synthesis of the 1,4-disubstituted pyrrolidinone derivatives 14-23

Aminotriazole 16 was obtained by heating potassium dithiocarbazate $\mathbf{1 4}$ with hydrazine hydrate or heating the corresponding 1,3,4-oxadiazole $\mathbf{1 5}$ with hydrazine hydrate in water. The resonances at $152.6 \mathrm{ppm}(\mathrm{C}=\mathrm{N})$ and at $171.1 \mathrm{ppm}(\mathrm{C}=\mathrm{S})$ in ${ }^{13} \mathrm{C}$ NMR spectrum as well as the ones at $5.56 \mathrm{ppm}\left(\mathrm{NH}_{2}\right)$ and $13.61 \mathrm{ppm}(\mathrm{NH} / \mathrm{SH})$ in ${ }^{1} \mathrm{H}$ NMR spectrum revealed the formation of the 5membered triazole 16. The condensation of aminotriazole 16 with aromatic aldehydes was carried out providing the corresponding Schiff bases 17, 18. Due to the abovementioned condensation reaction, the resonances of protons of the $\mathrm{NH}_{2}$ group (5.56 ppm) disappeared in ${ }^{1} \mathrm{H}$ NMR spectra of aminotriazole 16. Treatment of the 4-(4amino-5-thioxo-4,5-dihydro-1H-1,2,4-triazol-3-yl)-1-(4methoxyphenyl)-pyrrolidin-2-one (16) with 1.2 equivalents of ethyl chloroacetate in the presence of triethylamine resulted in the formation of the only $S$ alkylated product 19. During reaction of 4-amino-1,2,4triazole $\mathbf{1 6}$ with 2,5-hexanedione, performed in the refluxing 2-propanol in the presence of a catalytic amount of hydrochloric acid, the $N$-substituted pyrrole derivative 20 was synthesized. The formation of a 2,5dimethylpyrrole ring, included into the $\mathbf{2 0}$ composition, has been proven by the singlets at $1.98 \mathrm{ppm}\left(\mathrm{CH}_{3}\right)$, $5.95 \mathrm{ppm}(=\mathrm{CH})$, and $14.27 \mathrm{ppm}(\mathrm{NH})$ in ${ }^{1} \mathrm{H} \mathrm{NMR}$ spectrum. In the final stage of this synthetic work, the 4(6-(4-substituted phenyl)-7H-[1,2,4]triazolo[3,4b] $[1,3,4]$ thiadiazin-3-yl)-1-(4-methoxyphenyl)pyrrolidin2-ones 21-23 were synthesized from aminotriazole 16 and the corresponding $\alpha$-bromoketone in methanol in the presence of triethylamine. 


\section{Biology}

Results of DPPH scavenging activity screening. The antioxidative activity of the synthesized compounds was evaluated by the 2,2-diphenyl-1-(2,4,6trinitrophenyl)hydrazyl (DPPH) radical scavenging method. The effect of antioxidants on DPPH radical scavenging has been thought to be due to their hydrogen donating ability. The decrease in absorbance of the DPPH radical was caused by antioxidants because of the reaction between antioxidant molecules and the radical.

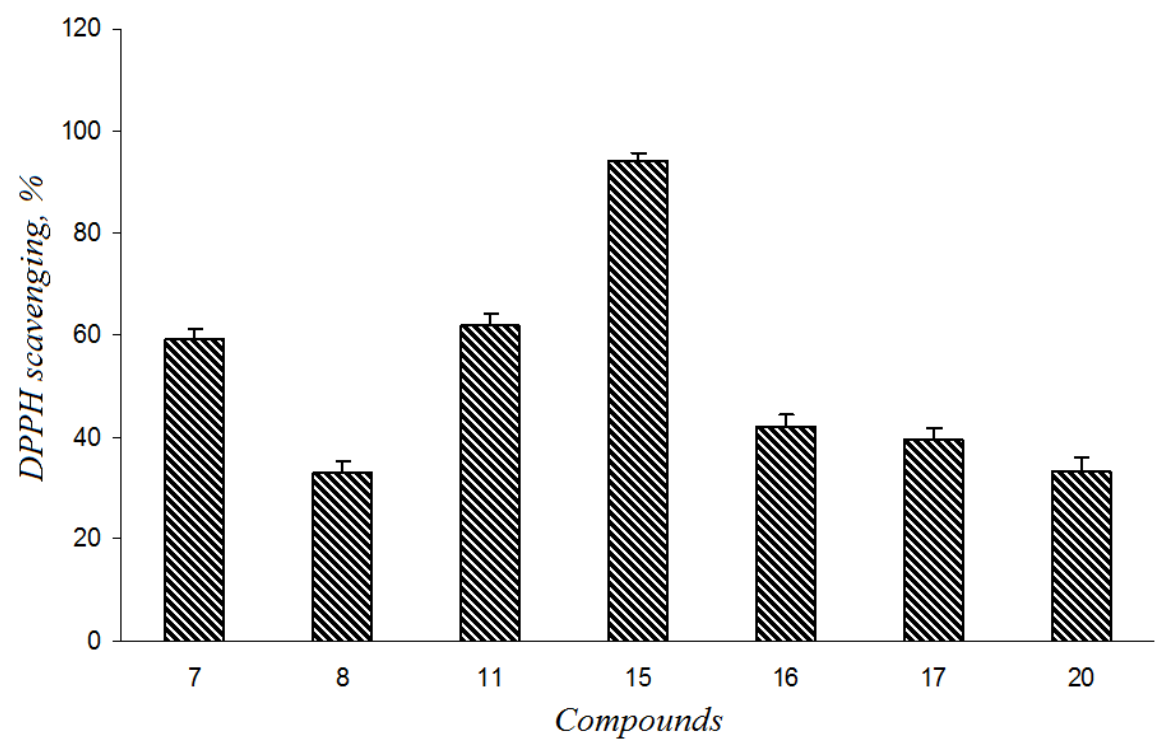

Fig. 1. DPPH scavenging activity

As seen from the results presented in Fig. 1, compound $\mathbf{1 5}$ showed a very high DPPH scavenging ability (92\%). Compounds $\mathbf{7}$ and $\mathbf{1 1}$ also showed an approx. $61 \%$ scavenging action. Antioxidative activity of compounds $8,16,17$, and 20 was moderate.

Results of antibacterial activity screening. The synthesized compounds $\mathbf{2 - 5}, \mathbf{9}, \mathbf{1 1}-\mathbf{1 3}$, and 15-23 were evaluated for their antibacterial activity against $R$. radiobacter, Xanthomonas campestris, Escherichia coli strains by using the diffusion technique. The activity of the tested compounds were compared with that of the known antibacterial agent ampicillin. $R$. radiobacter was sensitive to compounds $\mathbf{2 1 - 2 3}(1000 \mu \mathrm{g} / \mathrm{ml})$, however it was the most sensitive to compound $\mathbf{1 5}$ (concentrations $300-1000 \mu \mathrm{g} / \mathrm{ml}$ ). E. coli was sensitive to compounds 21 and $22(1000 \mu \mathrm{g} / \mathrm{ml})$ and $X$. campestris - to compound 22 $(1000 \mu \mathrm{g} / \mathrm{ml})$. Both microbial strains were most sensitive to compound 15 (concentrations $300-1000 \mu \mathrm{g} / \mathrm{ml}$ ).

The research presented herein has demonstrated that among all the compounds tested, compounds with 5thioxo-4,5-dihydro-1,3,4-oxadiazol-2-yl- and 6-phenyl$7 H$-[1,2,4]triazolo[3,4-b][1,3,4]thiadiazin-3-yl

substituents possess the highest antibacterial activity. The highest antibacterial activity was shown by 1-(4methoxyphenyl)-4-(4,5-dihydro-5-thioxo-1,3,4oxadiazol-2-yl)pyrrolidin-2-one (15). Based on these experiments, the antibacterial activity of the investigated compounds may be arranged in the following order:

$15>22>23>21$
Increasing antibacterial activity against Rhizobium radiobacter

As seen from the comparison of the antibacterial data for 21-23 series compounds, the introduction of substituents in the benzene ring has increased the antibacterial effect.

\section{Experimental section}

\section{Chemistry}

The starting materials and solvents were obtained from Sigma-Aldrich Chemie GmbH (Germany) and Fluka (Switzerland) and were used without further purification. The methods used to follow the reactions were TLC and NMR. The NMR spectra were recorded on a Varian Unity Inova (300 MHz) spectrometer (Varian, Inc., USA). Chemical shifts are expressed as $\delta$, ppm relative to TMS. IR spectra $\left(v, \mathrm{~cm}^{-1}\right)$ were recorded on a Perkin-Elmer BX FT-IR spectrometer (Perkin-Elmer Inc., USA) using $\mathrm{KBr}$ tablets. Mass spectra were obtained on a Waters ZQ 2000 spectrometer (Waters, Germany) using the atmospheric pressure chemical ionization (APCI) mode and operating at $25 \mathrm{~V}$. Elemental analyses were performed on a CE-440 elemental analyzer (Exeter Analytical Inc., USA). Melting points were determined on a B-540 Melting Point Analyzer (Büchi Corporation, USA) and are uncorrected. TLC was performed using Merck, Silica gel $60 \mathrm{~F}_{254}$ (Kieselgel $60 \mathrm{~F}_{254}$ ) silica gel plates. 
$N$-(2,5-Dimethyl-1H-pyrrol-1-yl)-1-(4methoxyphenyl)-5-oxopyrrolidine-3-carboxamide (2). A mixture of the hydrazide $1(2.50 \mathrm{~g}, 10 \mathrm{mmol}), 2,5-$ hexanedione $(2.28 \mathrm{~g}, 20 \mathrm{mmol})$, glacial acetic acid $(1 \mathrm{ml})$ and 2-propanol $(15 \mathrm{ml})$ was refluxed for $3 \mathrm{~h}$, the solvent was separated under reduced pressure, the residue was diluted with water $(50 \mathrm{ml})$, and the solution was heated to a gentle boil. The precipitate formed upon cooling the reaction mixture was filtered off, washed with water, dried and recrystallized from 2-propanol to give 2 (3.10 $\mathrm{g}, 95 \%)$ as a brownish solid. M.p. ${ }^{147-148}{ }^{\circ} \mathrm{C}(2-$ propanol).

IR $\left(\mathrm{KBr}, \mathrm{cm}^{-1}\right): 3259(\mathrm{NH}), 1682,1664(2 \mathrm{C}=\mathrm{O})$.

${ }^{1} \mathbf{H}$ NMR $\left(300 \mathrm{MHz}, \mathrm{DMSO}-\mathrm{d}_{6}\right): \delta_{\mathrm{H}} 2.00(6 \mathrm{H}, \mathrm{s}$, $\left.2 \mathrm{CH}_{3}\right), 2.67-2.91\left(2 \mathrm{H}, \mathrm{m}, \mathrm{CH}_{2} \mathrm{CO}\right), 3.43-3.51(1 \mathrm{H}, \mathrm{m}$, $\mathrm{CH}), 3.74\left(3 \mathrm{H}, \mathrm{s}, \mathrm{OCH}_{3}\right), 3.29-4.13\left(2 \mathrm{H}, \mathrm{m}, \mathrm{NCH}_{2}\right), 5.66$ $(2 \mathrm{H}, \mathrm{s}, 2 \mathrm{CH}), 7.57\left(2 \mathrm{H}, \mathrm{d}, J=9.0 \mathrm{~Hz}, \mathrm{H}_{\mathrm{ar}-3,5}\right), 7.96(2 \mathrm{H}$, d, $\left.J=9.0 \mathrm{~Hz}, \mathrm{H}_{\mathrm{ar}-2,6}\right), 10.92(1 \mathrm{H}, \mathrm{s}, \mathrm{NH})$

${ }^{13}$ C NMR $\left(75 \mathrm{MHz}\right.$, DMSO-d $\left.{ }_{6}\right): \delta_{\mathrm{C}} 10.9\left(\mathrm{CH}_{3}\right), 34.0$, 35.3, $50.6\left(\mathrm{C}_{\text {pyrrolid }}\right), 55.1\left(\mathrm{OCH}_{3}\right), 103.0(\mathrm{CH}), 113.8$, $121.3,132.2,155.9\left(\mathrm{C}_{\mathrm{ar}}\right), 126.7(\mathrm{C}-\mathrm{N}), 171.0,171.8$ $(2 \mathrm{C}=\mathrm{O})$.

MS (APCI) m/z: $328[\mathrm{M}+\mathrm{H}]^{+}(10 \%), 350[\mathrm{M}+\mathrm{Na}]^{+}$ $(100 \%), 351[\mathrm{M}+\mathrm{Na}+\mathrm{H}]^{+}(30 \%)$.

Calculated, \%: C 66.04, N 12.84, $\mathrm{H} \quad 6.47$. $\mathrm{C}_{18} \mathrm{H}_{21} \mathrm{~N}_{3} \mathrm{O}_{3}$.

Found, \%: C 66.21, N 12.92, H 6.44.

4-[(3,5-Dimethyl-1H-pyrazol-1-yl)carbonyl]-1-(4methoxyphenyl)pyrrolidin-2-one (3). A mixture of hydrazide 1 (2.50 g, $10 \mathrm{mmol}), 2,4$-pentanedione (2.00 g, $20 \mathrm{mmol})$, 2-propanol $(15 \mathrm{ml})$ and conc. hydrochloric acid $(0.5 \mathrm{ml})$ was heated under reflux for $2 \mathrm{~h}$, the solvent was separated under reduced pressure, the residue was diluted with water $(50 \mathrm{ml})$, and the solution was heated to a gentle boil. Upon cooling the reaction mixture, the precipitate was filtered off, washed with water, dried and crystallized from a mixture of 2-propanol and water (2:1) to give 3 ( $2.32 \mathrm{~g}, 74 \%)$ as a white solid. M.p. $94-95{ }^{\circ} \mathrm{C}$ (2-propanol and water).

IR $\left(\mathrm{KBr}, \mathrm{cm}^{-1}\right): 1727,1695(2 \mathrm{C}=\mathrm{O}), 1611(\mathrm{C}=\mathrm{N})$.

${ }^{1} \mathrm{H}$ NMR $\left(300 \mathrm{MHz}, \mathrm{CO}\left(\mathrm{CD}_{3}\right)_{2}\right): \delta_{\mathrm{H}} 2.19(3 \mathrm{H}, \mathrm{s}$, $\left.\mathrm{N}=\mathrm{C}-\mathrm{CH}_{3}\right), 2.48\left(3 \mathrm{H}, \mathrm{s}, \mathrm{N}-\mathrm{C}-\mathrm{CH}_{3}\right), 2.67-2.78(2 \mathrm{H}, \mathrm{m}$, $\left.\mathrm{CH}_{2} \mathrm{CO}\right), 3.74\left(3 \mathrm{H}, \mathrm{s}, \mathrm{OCH}_{3}\right), 4.01-4.25\left(2 \mathrm{H}, \mathrm{m}, \mathrm{NCH}_{2}\right)$, $4.48-4.58\left(1 \mathrm{H}, \mathrm{s}, \mathrm{CH}_{2} \mathrm{CH}\right), 6.11(1 \mathrm{H}, \mathrm{s}, \mathrm{CH}), 6.89(2 \mathrm{H}, \mathrm{d}$, $\left.J=9.2 \mathrm{~Hz}, \mathrm{H}_{\mathrm{ar}-3,5}\right), 7.57\left(2 \mathrm{H}, \mathrm{d}, J=9.2 \mathrm{~Hz}, \mathrm{H}_{\mathrm{ar}-2,6}\right)$.

${ }^{13}$ C NMR (75 MHz, DMSO- $\left.\mathrm{d}_{6}\right): \delta_{\mathrm{C}} 14.0,14.5$ $\left(2 \mathrm{CH}_{3}\right), 35.9,37.0,51.6\left(\mathrm{C}_{\text {pyrrolid }}\right), 55.8\left(\mathrm{OCH}_{3}\right), 112.3$ $(\mathrm{CCH}), 114.8,122.4,134.0,157.5\left(\mathrm{C}_{\mathrm{ar}}\right), 145.2(\mathrm{~N}-\mathrm{C}-$ $\left.\mathrm{CH}_{3}\right), 153.4\left(\mathrm{~N}=C-\mathrm{CH}_{3}\right), 171.9,173.8(2 \mathrm{C}=\mathrm{O})$. $(30 \%)$.

MS (APCI) m/z: $314[\mathrm{M}+\mathrm{H}]^{+} 315(80 \%)[\mathrm{M}+1+\mathrm{H}]^{+}$

Calculated, \%: C 65.16, N 13.41, $\mathrm{H}$ 6.11.

$\mathrm{C}_{17} \mathrm{H}_{19} \mathrm{~N}_{3} \mathrm{O}_{3}$.

Found, \%: C 65.42, N 13.20, H 6.34.

Ethyl $N$-\{[1-(4-methoxyphenyl)-5-oxopyrrolidin-3yl]carbonyl \}hydrazonoformate (4). A mixture of the hydrazide 1 (1.25 g, $5 \mathrm{mmol})$, and ethyl orthoformate $(10 \mathrm{ml})$ was heated to boiling and then cooled down. The formed residue was filtered off, washed with ether, dried, and crystallized from toluene to give $4(0.73 \mathrm{~g}, 48 \%)$ as a white solid. M.p. $163-164^{\circ} \mathrm{C}$ (toluene).

IR $\left(\mathrm{KBr}, \mathrm{cm}^{-1}\right): 3233(\mathrm{NH}), 1670,1615(2 \mathrm{C}=\mathrm{O})$, $1514(\mathrm{C}=\mathrm{N})$

${ }^{1} \mathbf{H}$ NMR $\left(300 \mathrm{MHz}, \mathrm{DMSO}-\mathrm{d}_{6}\right): \delta_{\mathrm{H}} 1.22-1.31(3 \mathrm{H}$, $\left.\mathrm{m}, \mathrm{CH}_{3}\right), 2.61-2.72\left(2 \mathrm{H}, \mathrm{m}, \mathrm{CH}_{2} \mathrm{CO}\right), 3.73(3 \mathrm{H}, \mathrm{s}$, $\left.\mathrm{OCH}_{3}\right), 3.77-4.21\left(5 \mathrm{H}, \mathrm{m}, \mathrm{OCH}_{2} \mathrm{CH}_{3}\right.$ and $\mathrm{CH}$ and $\left.\mathrm{CH}_{2} \mathrm{~N}\right), 6.85(1 \mathrm{H}(0.2 \mathrm{Z}), \mathrm{s}, \mathrm{CH}), 6.90(1 \mathrm{H}(0.5 \mathrm{Z}), \mathrm{s}, \mathrm{CH})$, $6.93\left(2 \mathrm{H}, \mathrm{d}, J=9.0 \mathrm{~Hz}, \mathrm{H}_{\mathrm{ar}-3,5}\right), 7.54(2 \mathrm{H}, \mathrm{d}, J=9.0 \mathrm{~Hz}$,

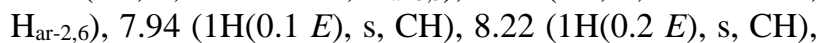
$10.05(1 \mathrm{H}(0.2 \mathrm{Z}), \mathrm{s} \mathrm{NH}), 10.54(1 \mathrm{H}(0.5 \mathrm{Z}), \mathrm{s}, \mathrm{NH}), 10.76$ $(1 \mathrm{H}(0.1 E), \mathrm{s}, \mathrm{NH}), 10.79(1 \mathrm{H}(0.2 E), \mathrm{s}, \mathrm{NH})$.

${ }^{1} \mathbf{H}$ NMR $\left(300 \mathrm{MHz}, \mathrm{CDCl}_{3}\right) \delta_{\mathrm{H}} 1.35(3 \mathrm{H}, \mathrm{t}, J=6.0$ $\left.\mathrm{Hz}, \mathrm{CH}_{3}\right), 2.75-3.02\left(2 \mathrm{H}, \mathrm{m}, \mathrm{CH}_{2} \mathrm{CO}\right), 3.77(3 \mathrm{H}, \mathrm{s}$, $\left.\mathrm{OCH}_{3}\right), \quad 3.90-4.17\left(5 \mathrm{H}, \mathrm{m}, \mathrm{OCH}_{2} \mathrm{CH}_{3}\right.$ and $\mathrm{CH}$ and $\left.\mathrm{CH}_{2} \mathrm{~N}\right), 6.44(1 \mathrm{H}(0.8 \mathrm{Z}), \mathrm{s}, \mathrm{CH}), 6.65(1 \mathrm{H}(0.2 \mathrm{E}), \mathrm{s}, \mathrm{CH})$, $6.87\left(2 \mathrm{H}, \mathrm{d}, J=9.0 \mathrm{~Hz}, \mathrm{H}_{\mathrm{ar}-3,5}\right), 7.47(2 \mathrm{H}, \mathrm{d}, J=9.0 \mathrm{~Hz}$, $\mathrm{H}_{\mathrm{ar}-2,6)}, 8.77(1 \mathrm{H}(0.8 \mathrm{Z}), \mathrm{s}, \mathrm{NH}), 9.06(1 \mathrm{H}(0.2 E), \mathrm{s}, \mathrm{NH})$.

${ }^{13} \mathrm{C}$ NMR $\left(75 \mathrm{MHz}, \mathrm{DMSO}-\mathrm{d}_{6}\right): \delta_{\mathrm{C}} 14.1,15.3,15.5$ $\left(\mathrm{OCH}_{2} \mathrm{CH}_{3}\right), 32.5,34.2,34.7,35.7,50.4,51.1\left(\mathrm{C}_{\text {pyrrolid }}\right)$, $55.2\left(\mathrm{OCH}_{3}\right), 62.5,67.2\left(\mathrm{OCH}_{2} \mathrm{CH}_{3}\right), 113.8,121.2,132.4$, $155.4\left(\mathrm{C}_{\mathrm{ar}}\right), 143.2,145.4,155.8,(\mathrm{CH}), 168.0,168.6$, $171.4,171,5(\mathrm{CONH})$.

${ }^{13} \mathrm{C}$ NMR $\left(75 \mathrm{MHz}, \mathrm{CDCl}_{3}\right) \delta_{\mathrm{C}} 15.4\left(\mathrm{OCH}_{2} \mathrm{CH}_{3}\right)$, 33.5, 35.2, $50.9\left(\mathrm{C}_{\text {pyrrolid }}\right), 55.5\left(\mathrm{OCH}_{3}\right), 68.1\left(\mathrm{OCH}_{2} \mathrm{CH}_{3}\right)$, $114.1,114.2,122.3,132.2,156.9\left(\mathrm{C}_{\mathrm{ar}}\right), 142.0,145.3$ $(2 \mathrm{CH}), 172.0,172.7(2 \mathrm{C}=\mathrm{O})$.

MS (APCI) m/z: $306[\mathrm{M}+\mathrm{H}]^{+}(10 \%), 328[\mathrm{M}+\mathrm{Na}]^{+}$ $(100 \%), 329[\mathrm{M}+\mathrm{Na}+\mathrm{H}]^{+}(30 \%)$.

Calculated, \%: C 59.01, N 13.76, H 6.27 . $\mathrm{C}_{15} \mathrm{H}_{19} \mathrm{~N}_{3} \mathrm{O}_{4}$

Found, \%: C 58.86, N 13.95, H 6.05.

1-(4-Methoxyphenyl)-4-(1,3,4-oxadiazol-2yl)pyrrolidin-2-one (5). A mixture of the hydrazide 1 $(2.50 \mathrm{~g}, 10 \mathrm{mmol})$, ethyl orthoformate $(11.86 \mathrm{~g}, 80 \mathrm{mmol})$ and $p$-toluenesulfonic acid $(0.1 \mathrm{~g}, 0.6 \mathrm{mmol})$ was heated under reflux for $20 \mathrm{~h}$ and then cooled down. The formed residue was filtered off, washed with water, dried, and crystallized from ethanol to give $5(2.20 \mathrm{~g}, 85 \%)$ as a white solid. M.p. $135-136{ }^{\circ} \mathrm{C}$ (from ethanol) in the literature [26] m.p. $133-134^{\circ} \mathrm{C}$ (from 2-propanol).

2-\{[1-(4-Methoxyphenyl)-5-oxopyrrolidin-3yl]carbonyl $\}-N$-phenylhydrazinecarboxamide (6). A mixture of hydrazide $\mathbf{1}(3.74 \mathrm{~g}, 15 \mathrm{mmol})$, phenyl isocyanate $(2.02 \mathrm{~g}, 17 \mathrm{mmol})$ and methanol $(20 \mathrm{ml})$ was stirred for $2 \mathrm{~h}$ at room temperature. The precipitate was filtered off, washed with methanol and water, crystallized from 1,4-dioxane to give $6(4.42 \mathrm{~g}, 80 \%)$ as a white solid. M.p. $157^{\circ} \mathrm{C}$ (from 1,4-dioxane decomp.).

IR $\left(\mathrm{KBr}, \mathrm{cm}^{-1}\right): 3312,3279,3197(3 \mathrm{NH}), 1673$, $1637,1610(3 \mathrm{C}=\mathrm{O})$.

${ }^{1} \mathbf{H}$ NMR $\left(300 \mathrm{MHz}\right.$, DMSO- $\left.\mathrm{d}_{6}\right): \delta_{\mathrm{H}} 2.62-2.82(2 \mathrm{H}$, $\left.\mathrm{m}, \mathrm{COCH}_{2}\right), 3.73\left(3 \mathrm{H}, \mathrm{s}, \mathrm{OCH}_{3}\right), 3.82-4.05(3 \mathrm{H}, \mathrm{m}, \mathrm{CH}$, $\left.\mathrm{NCH}_{2}\right), 6.91-7.55\left(9 \mathrm{H}, \mathrm{m}, \mathrm{H}_{\mathrm{ar}}\right), 8.10(1 \mathrm{H}(0.8 \mathrm{Z}), \mathrm{s}$, CONHPh), $8.43(1 \mathrm{H}(0.2 E), \mathrm{s}, \mathrm{CON} H \mathrm{Ph}), 8.80(1 \mathrm{H}(0.8$ $Z), \mathrm{s}, \mathrm{NHCONH}), 9.00(1 \mathrm{H}(0.2 E), \mathrm{s}, \mathrm{NHCONH}), 9.27$ $\left(1 \mathrm{H}(0.2 Z), s, \mathrm{~N} H \mathrm{COCH}_{\text {pyrrolid }}\right), 9.94(1 \mathrm{H}(0.8 E), \mathrm{s}$, $\mathrm{NHCOCH} \mathrm{Cyrrolid}$.

${ }^{13}$ C NMR (75 MHz, DMSO-d 6 ): $\delta_{\mathrm{C}} 33.6,35.1,50.6$ $\left(\mathrm{C}_{\text {pyrrolid }}\right), 55.0\left(\mathrm{OCH}_{3}\right), 113.7,118.3,121.1,121.6,128.5$, 
$132.1,132.0,139.3,155.3,155.9\left(\mathrm{C}_{\mathrm{ar}}\right), 171.0,171.1$, $172.4(3 \mathrm{C}=\mathrm{O})$.

MS (APCI) m/z: $369[\mathrm{M}+\mathrm{H}]^{+} \quad(100 \%), 370$

$[\mathrm{M}+1+\mathrm{H}]^{+}(50 \%)$.

Calculated, \%: C 61.95, N $15.21, \quad$ H 5.47 .

$\mathrm{C}_{19} \mathrm{H}_{20} \mathrm{~N}_{4} \mathrm{O}_{4}$.

Found, \%: 61.70, N 15.34; H 5.67.

2-\{[1-(4-Methoxyphenyl)-5-oxopyrrolidin-3yl]carbonyl $\}-N$-phenylhydrazinecarbothioamide (7). A mixture of the hydrazide $\mathbf{1}(4.98 \mathrm{~g}, 20 \mathrm{mmol})$, phenyl isothiocyanate $(2.70 \mathrm{~g}, 20 \mathrm{mmol})$ and methanol $(40 \mathrm{ml})$ was refluxed for $1 \mathrm{~h}$ and then cooled down. The precipitate was filtered off, washed with methanol, crystallized from 1,4-dioxane to give $7(5.80 \mathrm{~g}, 75 \%)$ as a white solid. M.p. $144-145^{\circ} \mathrm{C}(1,4$-dioxane).

IR $\left(\mathrm{KBr}, \mathrm{cm}^{-1}\right): 3314,3267,3180(3 \mathrm{NH}), 1714,1672$ $(2 \mathrm{C}=\mathrm{O}), 1247(\mathrm{C}=\mathrm{S})$.

${ }^{1} \mathbf{H}$ NMR $\left(300 \mathrm{MHz}, \mathrm{DMSO}-\mathrm{d}_{6}\right): \delta_{\mathrm{H}} 2.65-2.82(2 \mathrm{H}$, $\left.\mathrm{m}, \mathrm{CH}_{2} \mathrm{CO}\right), 3.33-3.34(1 \mathrm{H}, \mathrm{m}, \mathrm{CH}), 3.74\left(1 \mathrm{H}, \mathrm{s}, \mathrm{OCH}_{3}\right)$, 3.89-4.05 (2H, m, $\left.\mathrm{NCH}_{2}\right), 6.93-7.55\left(9 \mathrm{H}, \mathrm{m}, \mathrm{H}_{\mathrm{ar}}\right), 9.57$, $9.69,10.21(3 \mathrm{H}, 3 \mathrm{~s}, \mathrm{NH})$.

${ }^{13}$ C NMR (75 MHz, DMSO-d $\left.\mathrm{d}_{6}\right): \delta_{\mathrm{C}} 34.1,35.2,50.6$ ( $\left.\mathrm{C}_{\text {pyrrolid }}\right), 55.2\left(\mathrm{OCH}_{3}\right), 113.8,121.3,126.4,128.1,128.4$, $132.3,139.0,155.8\left(\mathrm{C}_{\mathrm{ar}}\right), 170.9,171.4(2 \mathrm{C}=\mathrm{O})$.

MS (APCI) m/z: $385[\mathrm{M}+\mathrm{H}]^{+}(30 \%), 407[\mathrm{M}+\mathrm{Na}]^{+}$ $(100 \%), 408[\mathrm{M}+\mathrm{H}+\mathrm{Na}]^{+}(40 \%)$.

Calculated, \%: C 59.36, N 14.57, H 5.24. $\mathrm{C}_{19} \mathrm{H}_{20} \mathrm{~N}_{4} \mathrm{O}_{3} \mathrm{~S}$.

Found, \%: C 59.14, N 14.61, H 5.36.

1-(4-Methoxyphenyl)-4-[5-(phenylamino)-1,3,4thiadiazol-2-yl]pyrrolidin-2-one (8). A mixture of thiosemicarbazide $7(0.54 \mathrm{~g}, 1.4 \mathrm{mmol})$ and sulphuric acid $(1 \mathrm{ml})$ was stirred at room temperature for $1 \mathrm{~h}$. Then $2 \%$ aqueous $\mathrm{Na}_{2} \mathrm{CO}_{3}$ solution was added to the reaction mixture to $\mathrm{pH} 10$. The formed residue was filtered off, washed with water and dried, crystallized from 1,4dioxane to give $\mathbf{8}(0.46 \mathrm{~g}, 90 \%)$ a white solid.

IR $\left(\mathrm{KBr}, \mathrm{cm}^{-1}\right): 3288(\mathrm{NH}), 1644(\mathrm{C}=\mathrm{O})$.

${ }^{1} \mathbf{H}$ NMR $\left(300 \mathrm{MHz}, \mathrm{DMSO}-\mathrm{d}_{6}\right): \delta_{\mathrm{H}} 2.76-3.05(2 \mathrm{H}$, $\left.\mathrm{m}, \mathrm{CH}_{2} \mathrm{CO}\right), 3.74\left(1 \mathrm{H}, \mathrm{s}, \mathrm{OCH}_{3}\right), 3.97-4.13(2 \mathrm{H}, \mathrm{m}$, $\left.\mathrm{NCH}_{2}\right), 4.22-4.28(1 \mathrm{H}, \mathrm{m}, \mathrm{CH}), 6.93-7.61\left(9 \mathrm{H}, \mathrm{m}, \mathrm{H}_{\mathrm{ar}}\right)$, $10.36(1 \mathrm{H}, \mathrm{s}, \mathrm{NH})$.

${ }^{13}$ C NMR (75 MHz, DMSO-d 6 ): $\delta_{\mathrm{C}} 32.2,37.9,52.9$ ( $\left.\mathrm{C}_{\text {pyrrolid }}\right), 54.9\left(\mathrm{OCH}_{3}\right), 113.5,117.0,121.1,121.5,128.7$, 131.9, 140.3, $155.6\left(\mathrm{C}_{\mathrm{ar}}\right), 160.1,164.2(2 \mathrm{C}=\mathrm{N}), 170.7$ $(\mathrm{C}=\mathrm{O})$.

MS (APCI) m/z: $367 \quad[\mathrm{M}+\mathrm{H}]^{+}(100 \%), \quad 368$ $[\mathrm{M}+1+\mathrm{H}]^{+}(40 \%)$.

Calculated, \%: C 62.28, N 15.29, $\mathrm{H} 4.95$. $\mathrm{C}_{19} \mathrm{H}_{18} \mathrm{~N}_{4} \mathrm{O}_{2} \mathrm{~S}$.

Found, \%: C 62.55, N 15.02, H 4.88.

4-[(4-Methoxyphenyl)amino]-3-(4-phenyl-5thioxo-4,5-dihydro-1H-1,2,4-triazol-3-yl)butanoic acid (9). A mixture of thiosemicarbazide $7(1.00 \mathrm{~g}, 2.6 \mathrm{mmol})$ and $20 \%$ sodium hydroxide solution $(25 \mathrm{ml})$ was heated under reflux for $3 \mathrm{~h}$ and then cooled down. Then the reaction mixture was acidified with acetic acid to $\mathrm{pH} 7$, the formed residue was filtered off, washed with water and dried to give $9(0.30 \mathrm{~g}, 30 \%)$ as a white solid. M.p. ${ }^{139-140}{ }^{\circ} \mathrm{C}$ (2-propanol).

IR $\left(\mathrm{KBr}, \mathrm{cm}^{-1}\right): 3600(\mathrm{OH}), 3370,3136(2 \mathrm{NH}), 1689$ $(\mathrm{C}=\mathrm{O}), 1250(\mathrm{C}=\mathrm{S})$.

${ }^{1} \mathbf{H}$ NMR $\left(300 \mathrm{MHz}, \mathrm{DMSO}-\mathrm{d}_{6}\right): \delta_{\mathrm{H}} 2.26-2.79(2 \mathrm{H}$, $\left.\mathrm{m}, \mathrm{CH}_{2} \mathrm{CO}\right), 2.90-2.99(1 \mathrm{H}, \mathrm{m}, \mathrm{CH}), 3.07-3.18(2 \mathrm{H}, \mathrm{m}$, $\left.\mathrm{CH}_{2} \mathrm{~N}\right), 3.60\left(3 \mathrm{H}, \mathrm{s}, \mathrm{OCH}_{3}\right), 5.48(1 \mathrm{H}$, br. s, $\mathrm{NH}), 6.06$ $\left(2 \mathrm{H}, \mathrm{d}, J=8.9 \mathrm{~Hz}, \mathrm{H}_{\mathrm{ar}-3,5}\right), 6.53\left(2 \mathrm{H}, \mathrm{d}, J=8.9 \mathrm{~Hz}, \mathrm{H}_{\mathrm{ar}-}\right.$ 2,6), 7.37-7.63 5H, (m, $\left.\mathrm{H}_{\mathrm{ar}}\right), 13.86(1 \mathrm{H}$, br. s, NNH).

${ }^{13} \mathrm{C}$ NMR $\left(75 \mathrm{MHz}, \mathrm{DMSO}-\mathrm{d}_{6}\right): \delta_{\mathrm{C}} 32.0,34.9,46.3$ $\left(\mathrm{C}_{\text {pyrrolid }}\right), 55.3\left(\mathrm{OCH}_{3}\right), 112.7,114.6,128.8,129.5,129.8$, 133.5, 141.5, $153.8(\mathrm{C}-4), 150.7(\mathrm{C}=\mathrm{N}), 167.6(\mathrm{C}=\mathrm{S})$, $173.1(\mathrm{C}=\mathrm{O})$.

MS (APCI) m/z: $453[\mathrm{H}+3 \mathrm{Na}]^{+}(70 \%)$.

Calculated, \%: C 59.36, N 14.57, H 5.24. $\mathrm{C}_{19} \mathrm{H}_{20} \mathrm{~N}_{4} \mathrm{O}_{3} \mathrm{~S}$.

Found, \%: C 59.57, N 14.33, H 4.49.

5-[1-(4-Methoxyphenyl)-5-oxopyrrolidin-3-yl]-4phenyl-2,4-dihydro-3H-1,2,4-triazol-3-one (10). A mixture of semicarbazide $6(1.00 \mathrm{~g}, 2.7 \mathrm{~mol})$ and $25 \mathrm{ml}$ of $2 \%$ aqueous $\mathrm{NaOH}$ solution was heated under reflux for $3 \mathrm{~h}$, cooled and acidified with $10 \%$ hydrochloric acid to $\mathrm{pH}$ 2. The formed residue was filtered off, washed with water and dried, crystallized from 1,4-dioxane to give $\mathbf{1 0}$ $(0.58 \mathrm{~g}, 61 \%)$ as a white solid. M.p. $174-175^{\circ} \mathrm{C}(1,4-$ dioxane).

IR $\left(\mathrm{KBr}, \mathrm{cm}^{-1}\right): 3184(\mathrm{NH}), 1704,1692(2 \mathrm{C}=\mathrm{O})$.

${ }^{1} \mathbf{H}$ NMR $\left(300 \mathrm{MHz}, \mathrm{DMSO}-\mathrm{d}_{6}\right): \delta_{\mathrm{H}} 2.53-2.73(2 \mathrm{H}$, $\left.\mathrm{m}, \mathrm{CH}_{2} \mathrm{CO}\right), 3.57-3.65(1 \mathrm{H}, \mathrm{m}, \mathrm{CH}), 3.72\left(1 \mathrm{H}, \mathrm{s}, \mathrm{OCH}_{3}\right)$, 3.75-3.97 (2H, m, $\left.\mathrm{NCH}_{2}\right), 6.92\left(2 \mathrm{H}, \mathrm{d}, J=9.0 \mathrm{~Hz}, \mathrm{H}_{\mathrm{ar}-}\right.$ $3,5), 7.44\left(2 \mathrm{H}, \mathrm{d}, J=9.0 \mathrm{~Hz}, \mathrm{H}_{\mathrm{ar}-2,6}\right), 7.45-7.59(5 \mathrm{H}, \mathrm{m}$, $\left.\mathrm{H}_{\mathrm{ar}}{ }^{\prime}\right), 11.87(1 \mathrm{H}, \mathrm{s}, \mathrm{NH})$.

${ }^{13} \mathrm{C}$ NMR $\left(75 \mathrm{MHz}, \mathrm{DMSO}-\mathrm{d}_{6}\right): \delta_{\mathrm{C}} 27.8,35.3,50.5$ $\left(\mathrm{C}_{\text {pyrrolid }}\right), 55.1\left(\mathrm{OCH}_{3}\right), 113.7,121.4,127.6,127.7,128.9$, $129.5,132.0,132.6,155.9\left(\mathrm{C}_{\mathrm{ar}}\right), 147.3(\mathrm{C}=\mathrm{N}), 154.6$, $170.7(2 \mathrm{C}=\mathrm{O})$.

MS (APCI) m/z: $373[\mathrm{M}+\mathrm{Na}]^{+}(100 \%)$.

Calculated, \%: C 65.13, N 15.99, H 5.18 . $\mathrm{C}_{19} \mathrm{H}_{18} \mathrm{~N}_{4} \mathrm{O}_{3}$.

Found, \%: C 65.32, N 15.75, H 5.04.

1-(4-Methoxyphenyl)-4-(4-phenyl-5-thioxo-4,5dihydro-1H-1,2,4-triazol-3-yl)pyrrolidin-2-one (11). Method A. A mixture of thiosemicarbazide 7 (1.00 g, 2.6 mol) and $25 \mathrm{ml}$ of $2 \%$ aqueous $\mathrm{NaOH}$ solution was heated under reflux for $3 \mathrm{~h}$, cooled and acidified with 10 $\% \mathrm{HCl}$ to $\mathrm{pH} \mathrm{2.} \mathrm{The} \mathrm{formed} \mathrm{residue} \mathrm{was} \mathrm{filtered} \mathrm{off,}$ washed with water and dried, crystallized from methanol to give $11(0.80 \mathrm{~g}, 84 \%)$ as a white solid. M.p. 267-268 ${ }^{\circ} \mathrm{C}$ (methanol).

Method B. A mixture of the compound 9 (0.38 g, $1 \mathrm{mmol}), 10 \% \mathrm{HCl}(7 \mathrm{ml})$ was heated to boiling and then cooled down. The formed residue was filtered off, washed with water and dried, crystallized from methanol to give $\mathbf{1 1}(0.33 \mathrm{~g}, 90 \%)$ as a white solid. $(\mathrm{C}=\mathrm{S})$.

IR $\left(\mathrm{KBr}, \mathrm{cm}^{-1}\right): 3047(\mathrm{NH}), 1701 \quad(\mathrm{C}=\mathrm{O}), 1249$

${ }^{1} \mathbf{H}$ NMR $\left(300 \mathrm{MHz}, \mathrm{DMSO}-\mathrm{d}_{6}\right): \delta_{\mathrm{H}} 2.53-2.76(2 \mathrm{H}$, $\left.\mathrm{m}, \mathrm{CH}_{2} \mathrm{CO}\right), 2.51-2.58(1 \mathrm{H}, \mathrm{m}, \mathrm{CH}), 3.72\left(3 \mathrm{H}, \mathrm{s}, \mathrm{OCH}_{3}\right)$, 3.75-4.02 (2H, m, NCH$), 6.92\left(2 \mathrm{H}, \mathrm{d}, J=9.0 \mathrm{~Hz}, \mathrm{H}_{\mathrm{ar}-}\right.$ 
3,5), $7.43\left(2 \mathrm{H}, \mathrm{d}, J=9.0 \mathrm{~Hz}, \mathrm{H}_{\mathrm{ar}-2,6}\right), 7.49-7.63(5 \mathrm{H}, \mathrm{m}$, $\left.\mathrm{H}_{\mathrm{ar}}{ }^{\prime}\right), 13.89(1 \mathrm{H}, \mathrm{s}, \mathrm{NH})$.

${ }^{13} \mathrm{C}$ NMR (75 MHz, DMSO-d $\left.{ }_{6}\right): \delta_{\mathrm{C}} 27.8,35.7,50.7$ ( $\left.\mathrm{C}_{\text {pyrrolid }}\right), 55.1\left(\mathrm{OCH}_{3}\right), 113.7,121.5,128.5,129.5,129.7$, 131.9, 133.4, $156.0\left(\mathrm{C}_{\mathrm{ar}}\right), 152.8(\mathrm{C}=\mathrm{N}), 168.3(\mathrm{C}=\mathrm{S})$, $170.5(\mathrm{C}=\mathrm{O})$.

MS (APCI) m/z: $389[\mathrm{M}+\mathrm{Na}]^{+}(100 \%)$.

Calculated, \%: $\mathrm{C}$ 62.28, $\mathrm{N} 15.29, \mathrm{H} 4.95$. $\mathrm{C}_{19} \mathrm{H}_{18} \mathrm{~N}_{4} \mathrm{O}_{2} \mathrm{~S}$.

Found, \%: C 62.54, N 15.21, H 4.96.

$N$-(2,5-Dioxo-2,5-dihydro-1H-pyrrol-1-yl)-1-(4methoxyphenyl)-5-oxopyrrolidine-3-carboxamide (12). A mixture of the hydrazide 1 (1.0 g, $4 \mathrm{mmol})$, maleic anhydride $(0.40 \mathrm{~g}, 4 \mathrm{mmol})$ and 1,4-dioxane (20 $\mathrm{ml}$ ) was heated under reflux for $3 \mathrm{~h}$, then cooled down, and the formed residue was filtered off, washed with 1,4dioxane, crystallized from 1,4-dioxane to give 12 (1.03 g, $78 \%$ ) as a white solid.

IR $\left(\mathrm{KBr}, \mathrm{cm}^{-1}\right): 3221,3048(2 \mathrm{NH}), 1723,1675$, 1636, $1620(4 \mathrm{C}=\mathrm{O})$.

${ }^{1} \mathbf{H}$ NMR $\left(300 \mathrm{MHz}, \mathrm{DMSO}-\mathrm{d}_{6}\right): \delta_{\mathrm{H}} 2.57-2.81(2 \mathrm{H}$, $\left.\mathrm{m}, \mathrm{COCH}_{2}\right), 3.34-3.37(1 \mathrm{H}, \mathrm{m}, \mathrm{CH}), 3.74\left(3 \mathrm{H}, \mathrm{s}, \mathrm{OCH}_{3}\right)$, 3.81-4.05 (2H, m, $\left.\mathrm{NCH}_{2}\right), 6.30,6.36(4 \mathrm{H}, 2 \mathrm{~d}, J=12,0$ $\left.\mathrm{Hz}, \mathrm{H}_{\text {pyrrole }}\right), 6.94\left(2 \mathrm{H}, \mathrm{d}, J=9.0 \mathrm{~Hz}, \mathrm{H}_{\mathrm{ar}-3,5}\right), 7.54(2 \mathrm{H}, \mathrm{d}$, $\left.J=9.0 \mathrm{~Hz}, \mathrm{H}_{\mathrm{ar}-2,6}\right), 10.44(1 \mathrm{H}, \mathrm{s}, \mathrm{NH})$.

${ }^{13} \mathrm{C}$ NMR $\left(75 \mathrm{MHz}, \mathrm{DMSO}-\mathrm{d}_{6}\right): \delta_{\mathrm{C}} 33.8,35.3,50.8$ ( $\left.\mathrm{C}_{\text {pyrrolid }}\right), 55.2\left(\mathrm{OCH}_{3}\right), 113.8,121.3,127.3,155.8\left(\mathrm{C}_{\mathrm{ar}}\right)$, 132.2, 132.4 ( $\left.\mathrm{C}_{\text {pyrrole }}\right), 162.6,167.0,171.0,171.2(4 \mathrm{C}=\mathrm{O})$. MS (APCI) m/z: $330[\mathrm{M}+\mathrm{H}]^{+}(100 \%)$.

Calculated, \%: $\mathrm{C}$ 58.36, $\mathrm{N} 12.76, \quad \mathrm{H} 4.59$. $\mathrm{C}_{16} \mathrm{H}_{15} \mathrm{~N}_{3} \mathrm{O}_{5}$.

Found, \%: C 58.18, N 12.53, H 4.90.

$N$-(1,3-Dioxo-1,3-dihydro-2H-isoindol-2-yl)-1-(4methoxyphenyl)-5-oxopyrrolidine-3-carboxamide (13). A mixture of the hydrazide 1 (1.0 g, $4 \mathrm{mmol})$, phthalic anhydride $(0.59 \mathrm{~g}, 4 \mathrm{mmol})$, and glacial acetic acid $(5 \mathrm{ml})$ was heated under reflux for $24 \mathrm{~h}$. The mixture was filtered off, the filtrate was diluted with water $(5 \mathrm{ml})$, and the formed residue was filtered off, washed with water, crystallized from 2-propanol to give $\mathbf{1 3}(0.65 \mathrm{~g}, 43$ $\%)$ as a white solid. M.p. $181-182^{\circ} \mathrm{C}$ (2-propanol).

IR $\left(\mathrm{KBr}, \mathrm{cm}^{-1}\right): 3526,3433,3309(3 \mathrm{NH}), 1743$, 1722, 1690, $1677(4 \mathrm{C}=\mathrm{O})$.

${ }^{1} \mathbf{H}$ NMR $\left(300 \mathrm{MHz}, \mathrm{DMSO}-\mathrm{d}_{6}\right): \delta_{\mathrm{H}} 2.57-2.90(2 \mathrm{H}$, $\left.\mathrm{m}, \mathrm{COCH}_{2}\right), 3.45-3.53(1 \mathrm{H}, \mathrm{m}, \mathrm{CH}), 3.69\left(3 \mathrm{H}, \mathrm{s}, \mathrm{OCH}_{3}\right)$, 3.83-4.12 (2H, m, $\left.\mathrm{NCH}_{2}\right), 6.91\left(2 \mathrm{H}, \mathrm{d}, J=9.0 \mathrm{~Hz}, \mathrm{H}_{\mathrm{ar}-}\right.$ 3,5), $7.50\left(2 \mathrm{H}, \mathrm{d}, J=9.0 \mathrm{~Hz}, \mathrm{H}_{\mathrm{ar}-2,6}\right), 7.87-7,94(4 \mathrm{H}, \mathrm{m}$, $\left.\mathrm{H}_{\mathrm{ar}}{ }^{\prime}\right), 10.98(1 \mathrm{H}, \mathrm{s}, \mathrm{NH})$.

${ }^{13}$ C NMR (75 MHz, DMSO-d $\left.\mathrm{d}_{6}\right): \delta_{\mathrm{C}} 33.4,34.9,50.2$ $\left(\mathrm{C}_{\text {pyrrolid }}\right), 54.8\left(\mathrm{OCH}_{3}\right), 113.4,121.0,123.4,129.0,131.7$, $134.9,155.5\left(\mathrm{C}_{\mathrm{ar}}\right), 164.6,170.5,171.9(4 \mathrm{C}=\mathrm{O})$.

MS (APCI) m/z: $380 \quad[\mathrm{M}+\mathrm{H}]^{+}(100 \%), \quad 381$ $[\mathrm{M}+1+\mathrm{H}]^{+}(40 \%)$.

Calculated, \%: $\mathrm{C}$ 63.32, $\mathrm{N}$ 11.08, $\mathrm{H} 4.52$. $\mathrm{C}_{20} \mathrm{H}_{17} \mathrm{~N}_{3} \mathrm{O}_{5}$.

Found, \%: C 63.48, N 10.87, H 4.76.

1-(4-Methoxyphenyl)-4-(5-thioxo-4,5-dihydro1,3,4-oxadiazol-2-yl)pyrrolidin-2-one (15). A mixture of the hydrazide $\mathbf{1}(7.48 \mathrm{~g} 30 \mathrm{mmol})$, potassium hydroxide (5.22 g, $93 \mathrm{mmol})$, carbon disulphide (4.26 g, $56 \mathrm{mmol})$ and methanol $(65 \mathrm{ml})$ was refluxed for $24 \mathrm{~h}$, cooled down to room temperature, acidified with hydrochloric acid $10 \%$ to $\mathrm{pH} 1$. The precipitate was filtered off, washed with water, dried and crystallized from ethanol to give $\mathbf{1 5}(5.56 \mathrm{~g}, 64 \%)$ as a white solid. $(\mathrm{C}=\mathrm{S})$.

IR $\left(\mathrm{KBr}, \mathrm{cm}^{-1}\right): 3056(\mathrm{NH}), 1658(\mathrm{C}=\mathrm{O}), 1248$

${ }^{1} \mathbf{H}$ NMR $\left(300 \mathrm{MHz}, \mathrm{DMSO}-\mathrm{d}_{6}\right): \delta_{\mathrm{H}} 2.76-2.99(2 \mathrm{H}$, $\left.\mathrm{m}, \mathrm{CH}_{2} \mathrm{CO}\right), 3.74$ (3H, s, $\left.\mathrm{OCH}_{3}\right), 3.89-3.96(1 \mathrm{H}, \mathrm{m}, \mathrm{CH})$, 4.01-4.20 (2H, m, NCH$), 6.95\left(2 \mathrm{H}, \mathrm{d}, J=9.0 \mathrm{~Hz}, \mathrm{H}_{\mathrm{ar}-}\right.$ 3,5), $7.53\left(2 \mathrm{H}, \mathrm{d}, J=9.0 \mathrm{~Hz}, \mathrm{H}_{\mathrm{ar}-2,6}\right), 14.78(1 \mathrm{H}, \mathrm{pl} . \mathrm{s}$, $\mathrm{NH})$.

${ }^{13}$ C NMR $\left(75 \mathrm{MHz}, \mathrm{DMSO}-\mathrm{d}_{6}\right): \delta_{\mathrm{C}} 27.9,34.8,50.1$ $\left(\mathrm{C}_{\text {pyrrolid }}\right), 55.2\left(\mathrm{OCH}_{3}\right), 113.8,121.5,131.9,156.0\left(\mathrm{C}_{\mathrm{ar}}\right)$, $163.9(\mathrm{C}=\mathrm{N}), 170.3(\mathrm{C}=\mathrm{O}), 177.9(\mathrm{C}=\mathrm{S})$.

MS (APCI) m/z: $292[\mathrm{M}+\mathrm{H}]^{+}(100 \%)$.

Calculated, \%: $\mathrm{C}$ 53.60, $\mathrm{N}$ 14.42, $\mathrm{H} 4.50$. $\mathrm{C}_{13} \mathrm{H}_{13} \mathrm{~N}_{3} \mathrm{O}_{3} \mathrm{~S}$.

Found, \%: C 53.78, N 14.38, H 4.37.

4-(4-Amino-5-thioxo-4,5-dihydro-1H-1,2,4-triazol3-yl)-1-(4-methoxyphenyl)pyrrolidin-2-one (16). Method A. A mixture of the hydrazide 1 (7.48 g 30 mmol), potassium hydroxide $(5.23 \mathrm{~g}, 93 \mathrm{mmol})$, carbon disulphide (4.29 g, $56 \mathrm{mmol})$, and methanol $(65 \mathrm{ml})$ was refluxed for $24 \mathrm{~h}$, cooled down to room temperature, and diethyl ether $(45 \mathrm{ml})$ was poured into the reaction mixture. The precipitate was filtered off, washed with diethyl ether $(3 \times 50 \mathrm{ml})$ and dried. A mixture of the obtained dry solid, hydrazine hydrate $(4.50 \mathrm{~g}, 90 \mathrm{mmol})$ and water $(10 \mathrm{ml})$ was refluxed for $8 \mathrm{~h}$. Then the mixture was cooled down to room temperature, neutralized with acetic acid to $\mathrm{pH} \mathrm{7,} \mathrm{the} \mathrm{formed} \mathrm{precipitate} \mathrm{of} \mathrm{the} \mathrm{residue}$ was filtered off, washed with water, dried, and crystallized from ethanol to give 16 (4.60 g, 50\%). Then the filtrate was acidified with $10 \%$ hydrochloric acid to pH 1 to give compound 15 (2.43 g, $28 \%$ ) (Specification iv in Scheme 2).

Method B. A mixture of the compound 15 (3.00 g, $14 \mathrm{mmol})$, hydrazine hydrate $(2.05 \mathrm{~g}, 40 \mathrm{mmol})$ and water $(10 \mathrm{ml})$ was refluxed for $24 \mathrm{~h}$, then cooled down, acidified with acetic acid to $\mathrm{pH}$ 6. The precipitate was filtered off, washed with water, dried, and crystallized from ethanol to give 16 (3.00 g, $70 \%$ ). M.p. $191-192{ }^{\circ} \mathrm{C}$ (ethanol). $(\mathrm{C}=\mathrm{S})$.

IR $\left(\mathrm{KBr}, \mathrm{cm}^{-1}\right): 3056(\mathrm{NH}), 1658(\mathrm{C}=\mathrm{O}), 1248$

${ }^{1} \mathbf{H}$ NMR (300 MHz, DMSO-d $)$ : $\delta_{\mathrm{H}} 2.79-2.98(2 \mathrm{H}$, $\left.\mathrm{m}, \mathrm{CH}_{2} \mathrm{CO}\right), 3.73\left(3 \mathrm{H}, \mathrm{s}, \mathrm{OCH}_{3}\right), 3.81-3.90(1 \mathrm{H}, \mathrm{m}, \mathrm{CH})$, 4.01-4.21 (2H, m, $\left.\mathrm{NCH}_{2}\right), 5.56\left(2 \mathrm{H}, \mathrm{s}, \mathrm{NH}_{2}\right), 6.94(2 \mathrm{H}, \mathrm{d}$, $\left.J=9.0 \mathrm{~Hz}, \mathrm{H}_{\mathrm{ar}-3,5}\right), 7.52\left(2 \mathrm{H}, \mathrm{d}, J=9.0 \mathrm{~Hz}, \mathrm{H}_{\mathrm{ar}-2,6}\right), 13.61$ $(1 \mathrm{H}, \mathrm{s}, \mathrm{NH})$.

${ }^{13}$ C NMR (75 MHz, DMSO-d 6 ): $\delta_{\mathrm{C}} 27.3,35.0,50.7$ $\left(\mathrm{C}_{\text {pyrrolid }}\right), 55.2\left(\mathrm{OCH}_{3}\right), 113.8,121.4,132.2,155.9\left(\mathrm{C}_{\mathrm{ar}}\right)$, $152.6(\mathrm{C}=\mathrm{N}), 167.1(\mathrm{C}=\mathrm{O}), 171.1(\mathrm{C}=\mathrm{S})$.

MS (APCI) m/z: $306[\mathrm{M}+\mathrm{H}]^{+}(90 \%), 307[\mathrm{M}+1+\mathrm{H}]^{+}$ $(20 \%)$.

Calculated, \%: $\quad \mathrm{C} \quad 51.13, \quad \mathrm{~N} 22.94, \quad \mathrm{H} 4.95$.

$\mathrm{C}_{13} \mathrm{H}_{15} \mathrm{~N}_{5} \mathrm{O}_{2} \mathrm{~S}$.

Found, \%: C 51.36, N 23.02, H 5.23. 
General synthetic procedure of 4-\{4-[aryl substituted amino]-5-thioxo-4,5-dihydro-1H-1,2,4triazol-3-yl\}-1-(4-methoxyphenyl)pyrrolidin-2-ones $(17,18)$.

A mixture of aminotriazole $(0.50 \mathrm{~g}, 1.6 \mathrm{mmol})$, the corresponding benzaldehyde (1.76 mmol), 2-propanol $(10 \mathrm{ml})$ and hydrochloric acid (2 drops) was refluxed for $8 \mathrm{~h}$ and cooled down. The precipitate was filtered off, washed with water, dried, and crystallized from 1,4dioxane to give $\mathbf{1 7}$ or $\mathbf{1 8}$.

4-\{4-[Benzylideneamino]-5-thioxo-4,5-dihydro1H-1,2,4-triazol-3-yl\}-1-(4-methoxyphenyl)pyrrolidin2-one (17) was obtained according to the general procedure from benzaldehyde to give a white solid $(0.25$ g, $40 \%$ ). M.p. $209-210{ }^{\circ} \mathrm{C}$ (1,4-dioxane).

IR $\left(\mathrm{KBr}, \mathrm{cm}^{-1}\right): 3052(\mathrm{NH}), 1667(\mathrm{C}=\mathrm{O}), 1610$ $(\mathrm{C}=\mathrm{N}), 1250(\mathrm{C}=\mathrm{S})$.

${ }^{1} \mathbf{H}$ NMR $\left(300 \mathrm{MHz}, \mathrm{DMSO}-\mathrm{d}_{6}\right): \delta_{\mathrm{H}} 2.84-2.98(2 \mathrm{H}$, $\left.\mathrm{m}, \mathrm{CH}_{2} \mathrm{CO}\right), 3.73\left(3 \mathrm{H}, \mathrm{s}, \mathrm{OCH}_{3}\right), 3.99-4.09(2 \mathrm{H}, \mathrm{m}$, $\left.\mathrm{NCH}_{2}\right), 4.17-4.22(1 \mathrm{H}, \mathrm{m}, \mathrm{CH}), 6.93(2 \mathrm{H}, \mathrm{d}, J=9.0 \mathrm{~Hz}$, $\left.\mathrm{H}_{\mathrm{ar}-3,5}\right), 7.90\left(2 \mathrm{H}, \mathrm{d}, J=9.0 \mathrm{~Hz}, \mathrm{H}_{\mathrm{ar}-2,6}\right), 7.51-7.64(5 \mathrm{H}$, $\left.\mathrm{m}, \mathrm{H}_{\mathrm{ar}}{ }^{\prime}\right), 10.12(1 \mathrm{H}, \mathrm{s}, \mathrm{N}=\mathrm{CH}), 13.95(1 \mathrm{H}, \mathrm{s}, \mathrm{NH})$.

MS (APCI) m/z: $394[\mathrm{M}+\mathrm{H}]^{+}(100 \%), 395$ $[\mathrm{M}+1+\mathrm{H}]^{+}(30 \%)$.

Calculated, \%: 61.05, N 17.80, H 4.87. $\mathrm{C}_{20} \mathrm{H}_{19} \mathrm{~N}_{5} \mathrm{O}_{2} \mathrm{~S}$. Found, \%: C 61.29, N 17. 57, H 4.81.

4-\{4-[(4-Methoxybenzylidene)amino]-5-thioxo-4,5dihydro-1H-1,2,4-triazol-3-yl\}-1-(4-

methoxyphenyl)pyrrolidin-2-one (18) was obtained according to the general procedure from 4methoxybenzaldehyde to give a white solid $(0.53 \mathrm{~g}, 78$ \%). M.p. $206-208^{\circ} \mathrm{C}(1,4-$ dioxane $)$ IR $\left(\mathrm{KBr}, \mathrm{cm}^{-1}\right): 3283$ $(\mathrm{NH}), 1691(\mathrm{C}=\mathrm{O}), 1602(\mathrm{C}=\mathrm{N}), 1242(\mathrm{C}=\mathrm{S})$.

${ }^{1} \mathbf{H}$ NMR $\left(300 \mathrm{MHz}, \mathrm{DMSO}-\mathrm{d}_{6}\right): \delta_{\mathrm{H}} 2.80-2.96(2 \mathrm{H}$, $\left.\mathrm{m}, \mathrm{CH}_{2} \mathrm{CO}\right), 3.73,3.84\left(6 \mathrm{H}, 2 \mathrm{~s}, 2 \mathrm{OCH}_{3}\right), 3.69-4.07(2 \mathrm{H}$, $\left.\mathrm{m}, \mathrm{NCH}_{2}\right), 4.15-4.21(1 \mathrm{H}, \mathrm{m}, \mathrm{CH}), 6.93,7.08,7.52,7.85$ $\left(8 \mathrm{H}, 4 \mathrm{~d}, J=9.0 \mathrm{~Hz}, \mathrm{H}_{\mathrm{ar}}\right), 9.88(1 \mathrm{H}, \mathrm{s}, \mathrm{N}=\mathrm{CH}), 13.91(1 \mathrm{H}$, $\mathrm{s}, \mathrm{NH})$.

MS (APCI) m/z: $424 \quad[\mathrm{M}+\mathrm{H}]^{+} \quad(100 \%), \quad 425$ $[\mathrm{M}+\mathrm{H}+1]^{+}(30 \%)$.

Calculated, \%: 59.56, N 16.54, H 5.00. $\mathrm{C}_{21} \mathrm{H}_{21} \mathrm{~N}_{5} \mathrm{O}_{3} \mathrm{~S}$. Found, \%: C 59.54, N 16.66, H 5.17.

Ethyl (\{4-amino-5-[1-(4-methoxyphenyl)-5oxopyrrolidin-3-yl]-4H-1,2,4-triazol-3-

yl\}sulfanyl)acetate (19). A mixture of the aminotriazole 16 (1.53 g, $5.0 \mathrm{mmol})$, ethyl chloroacetate $(0.74 \mathrm{~g}, 6$ mmol $)$, triethylamine $(0.71 \mathrm{~g}, 7 \mathrm{mmol})$ and 2-propanol $(15 \mathrm{ml})$ was refluxed for $7 \mathrm{~h}$ and cooled down. The precipitate was filtered off, washed with water, dried, and crystallized from methanol to give $19(1.31 \mathrm{~g}, 67 \%)$ as a yellow solid. M.p. $203-204{ }^{\circ} \mathrm{C}$ (methanol).

IR $\left(\mathrm{KBr}, \mathrm{cm}^{-1}\right): 3345\left(\mathrm{NH}_{2}\right), 1732(\mathrm{C}=\mathrm{O}), 1674$, $1642(2 \mathrm{C}=\mathrm{N})$.

${ }^{1} \mathbf{H}$ NMR $\left(300 \mathrm{MHz}\right.$, DMSO-d $\left.\mathrm{d}_{6}\right): \delta_{\mathrm{H}} 1.18(3 \mathrm{H}, \mathrm{t}, J=$ $\left.8.0 \mathrm{~Hz}, \mathrm{CH}_{3}\right), 2.81-2.98\left(2 \mathrm{H}, \mathrm{m}, \mathrm{NCH}_{2}\right), 3.74(3 \mathrm{H}, \mathrm{s}$, $\left.\mathrm{OCH}_{3}\right), 3.86-3.96(1 \mathrm{H}, \mathrm{m}, \mathrm{CH}), 4.01-4.21(2 \mathrm{H}, \mathrm{m}$, $\left.\mathrm{CH}_{2} \mathrm{CO}\right), 4.04\left(2 \mathrm{H}, \mathrm{s}, \mathrm{CH}_{2}\right), 4.10(2 \mathrm{H}, \mathrm{q}, J=8.0 \mathrm{~Hz}$, $\left.\mathrm{CH}_{2} \mathrm{CH}_{3}\right), 5.84\left(2 \mathrm{H}, \mathrm{s}, \mathrm{NH}_{2}\right), 6.95\left(2 \mathrm{H}, \mathrm{d}, J=8.0 \mathrm{~Hz}, \mathrm{H}_{\mathrm{ar}-}\right.$ $3,5), 7.53\left(2 \mathrm{H}, \mathrm{d}, J=8.0 \mathrm{~Hz}, \mathrm{H}_{\mathrm{ar}-2,6}\right)$.
${ }^{13}$ C NMR (75 MHz, DMSO-d 6$): \delta_{\mathrm{C}} 14.1\left(\mathrm{CH}_{3}\right), 26.8$ $\left(\mathrm{SCH}_{2}\right), 33.0,36.1,51.5\left(\mathrm{C}_{\text {pyrrolid }}\right), 55.3\left(\mathrm{OCH}_{3}\right), 61.2$ $\left(\mathrm{CH}_{2} \mathrm{CH}_{3}\right), 113.9,121.4,132.4,155.9\left(\mathrm{C}_{\mathrm{ar}}\right), 151.8(\mathrm{C}=\mathrm{N})$, $156.7(\mathrm{C}-\mathrm{S}), 168.5,171.4(2 \mathrm{C}=\mathrm{O})$.

MS (APCI) m/z: $392[\mathrm{M}+\mathrm{H}]^{+}(100 \%)$.

Calculated, \%: 52.16, N 17.89, H 5.41. $\mathrm{C}_{17} \mathrm{H}_{21} \mathrm{~N}_{5} \mathrm{O}_{4} \mathrm{~S}$. Found, \%: C 52.39, N 17.62, H 5.61.

\section{4-[4-(2,5-Dimethyl-1H-pyrrol-1-yl)-5-thioxo-4,5-} dihydro-1H-1,2,4-triazol-3-yl]-1-(4methoxyphenyl)pyrrolidin-2-one (20). A mixture of the aminotriazole 16 (1.00 g, $3.3 \mathrm{mmol}), 2,5$-hexanedione $(0.57 \mathrm{~g}, 5 \mathrm{mmol})$, ethanol $(10 \mathrm{ml})$, and hydrochloric acid (2 drops) was refluxed for $7 \mathrm{~h}$ and cooled down. The precipitate was filtered off, washed with water, dried, and crystallized from 1,4-dioxane to give 20 (1.06 g, $84 \%$ ) as a white solid. M.p. $201-202{ }^{\circ} \mathrm{C}(1,4-d i o x a n e)$.

IR $\left(\mathrm{KBr}, \mathrm{cm}^{-1}\right): 3051(\mathrm{NH}), 1700(\mathrm{C}=\mathrm{O}), 1630$ $(\mathrm{C}=\mathrm{N}), 1253(\mathrm{C}=\mathrm{S})$.

${ }^{1} \mathbf{H}$ NMR $\left(300 \mathrm{MHz}, \mathrm{DMSO}-\mathrm{d}_{6}\right): \delta_{\mathrm{H}} 1.98(6 \mathrm{H}, \mathrm{s}$, $\left.\mathrm{CH}_{3}\right), 2.45-2.80\left(2 \mathrm{H}, \mathrm{m}, \mathrm{CH}_{2} \mathrm{CO}\right), 3.48-3.56(1 \mathrm{H}, \mathrm{m}$, $\mathrm{CH}), 3.73\left(3 \mathrm{H}, \mathrm{s}, \mathrm{OCH}_{3}\right), 3.80-4.07\left(2 \mathrm{H}, \mathrm{m}, \mathrm{NCH}_{2}\right), 5.95$ (2H, s, CH-CH), $6.93\left(2 \mathrm{H}, \mathrm{d}, J=9.0 \mathrm{~Hz}, \mathrm{H}_{\mathrm{ar}-3,5}\right), 7.45$ (2H, d, $\left.J=9.0 \mathrm{~Hz}, \mathrm{H}_{\mathrm{ar}-2,6}\right), 14.27(1 \mathrm{H}, \mathrm{s}, \mathrm{NH})$.

${ }^{13} \mathrm{C}$ NMR $\left(75 \mathrm{MHz}, \mathrm{DMSO}-\mathrm{d}_{6}\right): \delta_{\mathrm{C}} 11.0\left(2 \mathrm{CH}_{3}\right)$, 27.6, 35.2, 50.2 ( $\left.\mathrm{C}_{\text {pyrrolid }}\right), 55.3\left(\mathrm{OCH}_{3}\right), 105.8(\mathrm{CH}-\mathrm{CH})$, 113.9, 121.6, 131.8, 156.1 $\left(\mathrm{C}_{\mathrm{ar}}\right), 127.4\left(\mathrm{CH}_{3} \mathrm{C}\right), 152.2$ $(\mathrm{C}=\mathrm{N}), 167.7(\mathrm{C}=\mathrm{S}), 170.3(\mathrm{C}=\mathrm{O})$.

MS (APCI) m/z: $384[\mathrm{M}+\mathrm{H}]^{+}(100 \%)$.

Calculated, \%: 59.51, N 18.26, H 5.52. $\mathrm{C}_{19} \mathrm{H}_{21} \mathrm{~N}_{5} \mathrm{O}_{2} \mathrm{~S}$.

Found, \%: C 59.69, N 18.01, H 5.62.

4-(6-(4-Substituted phenyl)-7-bromoaceto$[1,2,4]$ triazolo[3,4-b][1,3,4]thiadiazin-3-yl)-1-(4methoxyphenyl)pyrrolidin-2-ones (21-23)

A mixture of the aminotriazole $16(0.31 \mathrm{~g}, 1 \mathrm{mmol})$, the corresponding $\alpha$-haloketone $(1.2 \mathrm{mmol})$, triethylamine $(0.12 \mathrm{~g}, 1.2 \mathrm{mmol})$, and methanol $(7 \mathrm{ml})$ was refluxed for $4 \mathrm{~h}$ and cooled down. The precipitates were filtered off, washed with water, dried, and crystallized from methanol to give 21-23.

1-(4-Methoxyphenyl)-4-(6-phenyl-7H$[1,2,4]$ triazolo[3,4-b][1,3,4] thiadiazin-3-yl)pyrrolidin2-one (21) was obtained according to the general procedure from 2-bromoacetophenone to give a white solid $(0.23$ g, $57 \%)$. M.p. $86-87^{\circ} \mathrm{C}$ (methanol). $(3 \mathrm{C}=\mathrm{N})$.

IR $\left(\mathrm{KBr}, \mathrm{cm}^{-1}\right): 1699(\mathrm{C}=\mathrm{O}), 1513,1464,1466$

${ }^{1} \mathbf{H}$ NMR $\left(300 \mathrm{MHz}, \mathrm{DMSO}-\mathrm{d}_{6}\right): \delta_{\mathrm{H}} 2.92-3.08(2 \mathrm{H}$, $\left.\mathrm{m}, \mathrm{CH}_{2} \mathrm{CO}\right), 3.74\left(3 \mathrm{H}, \mathrm{s}, \mathrm{OCH}_{3}\right), 4.10-4.18(2 \mathrm{H}, \mathrm{m}$, $\left.\mathrm{NCH}_{2}\right), 4.28(\mathrm{t}, 1 \mathrm{H}, J=8.4 \mathrm{~Hz}, \mathrm{CH}), 4.43\left(2 \mathrm{H}, \mathrm{s}, \mathrm{SCH}_{2}\right)$, $6.94\left(2 \mathrm{H}, \mathrm{d}, J=9.1 \mathrm{~Hz}, \mathrm{H}_{\mathrm{ar}-3,5}\right), 6.90-8.04\left(9 \mathrm{H}, \mathrm{m}, \mathrm{H}_{\mathrm{ar}}\right)$.

${ }^{13} \mathrm{C}$ NMR (75 MHz, DMSO-d 6$): \delta_{\mathrm{C}} 23.0\left(\mathrm{SCH}_{2}\right)$, 27.0, 35.8, 51.1 ( $\left.\mathrm{C}_{\text {pyrrolid }}\right), 55.2\left(\mathrm{OCH}_{3}\right), 113.8,121.4$, $127.5,129.0,132.0,132.3,133.4,153.1\left(\mathrm{C}_{\mathrm{ar}}\right), 141.3$ $\left(\mathrm{CH}_{2}-\mathrm{C}=\mathrm{N}\right), 155.1,155.9(2 \mathrm{C}=\mathrm{N}), 171.2(\mathrm{C}=\mathrm{O})$.

Calculated, \%: C 62.21, N 17.27, H 4.72. $\mathrm{C}_{21} \mathrm{H}_{19} \mathrm{~N}_{5} \mathrm{O}_{2} \mathrm{~S}$.

Found, \%: C 62.45, N 17.42, H 4.97. 
4-[6-(4-Chlorophenyl)-7H-[1,2,4]triazolo[3,4b] $[1,3,4]$ thiadiazin-3-yl]-1-(4-

methoxyphenyl)pyrrolidin-2-one (22) was as obtained according to the general procedure from 4-chloro-2'bromoacetophenone to give a white solid $(0.33 \mathrm{~g}, 75 \%)$. M.p. $209-210^{\circ} \mathrm{C}$ (methanol).

IR $\left(\mathrm{KBr}, \mathrm{cm}^{-1}\right): 1676(\mathrm{C}=\mathrm{O}), 1510,1496,1467$ $(3 \mathrm{C}=\mathrm{N})$.

${ }^{1} \mathbf{H}$ NMR $\left(300 \mathrm{MHz}\right.$, DMSO-d $\left.\mathrm{d}_{6}\right): \delta 2.90-3.07(2 \mathrm{H}$, $\left.\mathrm{m}, \mathrm{CH}_{2} \mathrm{CO}\right), 3.74\left(3 \mathrm{H}, \mathrm{s}, \mathrm{OCH}_{3}\right), 4.10-4.18(2 \mathrm{H}, \mathrm{m}$, $\left.\mathrm{NCH}_{2}\right), 4.24-4.30(1 \mathrm{H}, \mathrm{m}, \mathrm{CH}), 4.42\left(2 \mathrm{H}, \mathrm{s}, \mathrm{SCH}_{2}\right), 6.94$ $\left(2 \mathrm{H}, \mathrm{d}, J=9.1 \mathrm{~Hz}, \mathrm{H}_{\mathrm{ar}-3,5}\right), 7.56\left(2 \mathrm{H}, \mathrm{d}, J=9.1 \mathrm{~Hz}, \mathrm{H}_{\mathrm{ar}-}\right.$

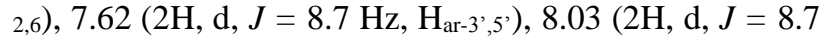
$\left.\mathrm{Hz}, \mathrm{H}_{\mathrm{ar}-2}, 6^{\prime}\right)$.

${ }^{13} \mathrm{C}$ NMR (75 MHz, DMSO-d 6 ): $\delta 22.9\left(\mathrm{SCH}_{2}\right), 27.0$, 35.8, $51.1\left(\mathrm{C}_{\text {pyrrolid }}\right), 55.2\left(\mathrm{OCH}_{3}\right), 113.8,121.4,129.1$, $129.3,132.2,132.3,136.8,153.9\left(\mathrm{C}_{\mathrm{ar}}\right), 141.2\left(\mathrm{CH}_{2-}\right.$ $C=\mathrm{N}), 154.0,155.9(2 \mathrm{C}=\mathrm{N}), 171.2(\mathrm{C}=\mathrm{O})$.

Calculated, \%: C 57.34, N 15.92, H 4.12. $\mathrm{C}_{21} \mathrm{H}_{18} \mathrm{ClN}_{5} \mathrm{O}_{2} \mathrm{~S}$.

Found, \%: C 57.53, N 16.05, H 4.37.

1-(4-Methoxyphenyl)-4-[6-(4-nitrophenyl)-7H$[1,2,4]$ triazolo[3,4-b][1,3,4]thiadiazin-3-yl]pyrrolidin2-one (23) was as obtained according to the general procedure from 4-nitro-2'-bromoacetophenone to give a brown solid $(0.35 \mathrm{~g}, 78 \%)$. M.p. $212-213{ }^{\circ} \mathrm{C}$ (methanol). $(3 \mathrm{C}=\mathrm{N})$.

IR $\left(\mathrm{KBr}, \mathrm{cm}^{-1}\right): 1684(\mathrm{C}=\mathrm{O}), 1512,1498,1467$

${ }^{1} \mathbf{H}$ NMR $(300 \mathrm{MHz}$, DMSO-d 6$): \delta_{\mathrm{H}} 2.88-3.12(2 \mathrm{H}$, $\left.\mathrm{m}, \mathrm{CH}_{2} \mathrm{CO}\right), 3.73\left(3 \mathrm{H}, \mathrm{s}, \mathrm{OCH}_{3}\right), 4.11-4.21(2 \mathrm{H}, \mathrm{m}$, $\left.\mathrm{NCH}_{2}\right), 4.24-4.331 \mathrm{H},(\mathrm{m}, \mathrm{CH}), 4.49\left(2 \mathrm{H}, \mathrm{s}, \mathrm{SCH}_{2}\right), 6.94$ $\left(2 \mathrm{H}, \mathrm{d}, J=9.0 \mathrm{~Hz}, \mathrm{H}_{\mathrm{ar}-3,5}\right), 7.56\left(2 \mathrm{H}, \mathrm{d}, J=9.0 \mathrm{~Hz}, \mathrm{H}_{\mathrm{ar}-}\right.$ 2,6), $8.25\left(2 \mathrm{H}, \mathrm{d}, J=8.9 \mathrm{~Hz}, \mathrm{H}_{\mathrm{ar}-2{ }^{\prime}, 6^{\prime}}\right), 8.35(2 \mathrm{H}, \mathrm{d}, J=8.9$

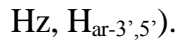

${ }^{13} \mathrm{C}$ NMR $\left(75 \mathrm{MHz}, \mathrm{DMSO}-\mathrm{d}_{6}\right): \delta_{\mathrm{C}} 23.1\left(\mathrm{SCH}_{2}\right)$, 27.0, 35.7, 51.1 ( $\left.\mathrm{C}_{\text {pyrrolid }}\right), 55.2\left(\mathrm{OCH}_{3}\right), 113.8,121.4$, $123.9,128.9,132.3,139.3,149.1,153.3\left(\mathrm{C}_{\mathrm{ar}}\right), 141.1$ $\left(\mathrm{CH}_{2}-\mathrm{C}=\mathrm{N}\right), 154.1,155.9(2 \mathrm{C}=\mathrm{N}), 171.1(\mathrm{C}=\mathrm{O})$.

Calculated, \%: C 55.99, N 18.66, H 4.03. $\mathrm{C}_{21} \mathrm{H}_{18} \mathrm{~N}_{6} \mathrm{O}_{4} \mathrm{~S}$.

Found, \%: C 56.15, N 18.82, H 4.17.

\section{Biology}

Method for determination of antioxidant activity. The free radical scavenging activity of the compounds was measured by the widely used DPPH method [27]. Briefly, $1 \mathrm{~cm}^{3}$ of a $1 \mathrm{mM}$ solution of DPPH in ethanol was added to the solutions of tested compounds $(1 \mathrm{mg}$ $\mathrm{cm}^{-3}$ in DMSO). The mixture was shaken vigorously and allowed to stand at room temperature for $20 \mathrm{~min}$. Afterwards, the absorbance was measured at $517 \mathrm{~nm}$ in a spectrophotometer (UV-200-RS). The lower absorbance of the reaction mixture indicated a higher free radical scavenging activity. The capability to scavenge the DPPH radical was calculated according to the following equation: DPPH scavenging effect $\%=\left(\mathrm{A}_{0}-\mathrm{A}_{1} / \mathrm{A}_{0}\right) \times 100$, where $\mathrm{A}_{0}$ is the absorbance of the control reaction, and $\mathrm{A}_{1}$ is the absorbance in the presence of the samples.

Microbiology. The antibacterial activity was tested by using the disk diffusion technique. The microbial strains $R$. radiobacter, X. campestris, and E.coli were commercially available from the German Collection of Microorganisms and Cell Cultures (DSMZ). The zone of inhibition of bacterial growth was investigated. The main solutions $\left(1 \mathrm{mg} / \mathrm{cm}^{3}\right)$ of the synthesized compounds were prepared in DMSO and diluted to different concentrations $\left(250,300,400,450,500,750,1,000 \mu \mathrm{g} / \mathrm{cm}^{3}\right)$ with DMSO. Cultures of $R$. radiobacter, X. campestris, and $E$. coli were cultivated in Petri dishes for $24 \mathrm{~h}$ at $37{ }^{\circ} \mathrm{C}$ on the Luria-Bertani (LB) agar medium. A bacterial suspension was prepared from cultivated bacterial cultures, and $50 \mathrm{~mm}^{3}$ of the inoculum containing bacterial cells $\left(10^{8} \mathrm{CFU} / \mathrm{cm}^{3}\right)$ was spread over the LB agar medium. Filter paper disks were prepared by adding 25 $\mathrm{mm}^{3}$ of each compound solution and then placed on the LB agar medium. Ampicillin was used as the positive control.

\section{Conclusions}

A variety of 4-substituted 1-(4metoxyphenyl)pyrrolidin-2-ones containing azole, diazole, oxadiazole, thiadiazole, and triazole fragments were synthesized from 1-(metoxyphenyl)-5oxopyrrolidine-3-carbohydrazide by condensation reactions or by the modification of the obtained compounds. All structures of the new compounds described here have been confirmed by the synthetic, analytical, and spectroscopic data. All compounds were screened for antibacterial activity and only two types of hetero systems - 5-thioxo-4,5-dihydro-1,3,4-oxadiazole and $[1,2,4]$ triazolo $[3,4-b][1,3,4]$ thiadiazine - showed a moderate activity against $R$. radiobacter, X. campestris, and E. coli microorganisms. Some compounds were tested for their antioxidant activity. The best activity was shown by 1-(4-methoxyphenyl)-4-(4,5-dihydro-5-thioxo1,3,4-oxadiazol-2-yl)pyrrolidin-2-one, whereas the displacement of the oxygen atom by the nitrogen one in the 1,3,4-oxadiazole ring decreased the antioxidant activity.

\section{References}

1. Arora S. K., Sinha N., Jain S., Upadhayaya R. S., Jana G., Ajay S., Sinha R. K. U. S. Pat. 7763602 B2, 2010.

2. El-Gaby M. S. A., Gaber A. M., Atalla A. A., Abd AlWahab K. A. Novel synthesis and antifungal activity of pyrrole and pyrrolo[2,3- $d$ ]pyrimidine derivatives containing sulfonamido moieties // Il Farmaco. 2002. Vol. 57. P. 613617.

http://dx.doi.org/10.1016/S0014-827X(01)01178-8.

3. Vaickelionienė R., Mickevičius V., Mikulskienė G., Stasevych M., Komarovska-Porokhnyavets O., Novikov V. Reactions of 5-oxo-1-phenylpyrrolidine-3carbohydrazides with 1,4-naphthoquinone derivatives and the properties of the obtained products // Res. Chem. Intermed. 2011. Vol. 37. N 8. P. 1009-1027. http://dx.doi.org/10.1007/s11164-011-0306-y.

4. El-Kashef H. S., El-Emary T. I., Gasquet M., TimonDavid P., Maldonado J., Vanelle P. New pyrazolo[3,4b]pyrazines: synthesis and biological activity // Pharmazie. 2000. Vol. 55. P. 572-576. 
5. Tumosienė I., Kantminienė K., Pavilionis A., Maželienė Ž., Beresnevičius Z. Synthesis of azole derivatives from 3phenylaminopropanohydrazide and evaluation of their antimicrobial efficacy // Heterocycles. 2009. Vol. 78. P. 5970. http://dx.doi.org/10.3987/COM-08-11478.

6. Alsterholm M., Karami N., Faergeman J. Antimicrobial activity of topical skin pharmaceuticals - an in vitro study // Acta Derm. Venereol. 2010. Vol. 90. P. 239-245. http://dx.doi.org/10.2340/00015555-0840.

7. Tumosienė I., Jonuškienė I., Kantminienė K., Beresnevičius $\mathbf{Z}$. The synthesis of azole derivatives from 3[(4-methylphenyl)amino]propanehydrazide and its N'phenylcarbamoyl derivatives, and theirantibacterial activity // Monatsh. Chem. 2012. Vol. 143. N 10. P. 1441-1450. http://dx.doi.org/10.1007/s00706-012-0799-0.

8. Hof H. Critical annotations to the use of azole antifungals for plant protection // Antimicrob. Agents Chemother. 2001. Vol. 45. N 11. P. 2987-2990. http://dx.doi.org/10.1128/AAC.45.11.2987-2990.2001.

9. Walter H. New carboxylic acid amides of the pyrrole series: Synthetic routes and biological aspects // Z. Naturforsch. 2008. Vol. 63 b. P. 351-362.

10. Cook J., Shulman I., Bielak J. J. U. S. Patent 6984602 B2, 2006.

11. Qian X., Zhang R. Syntheses and insecticidal activities of novel 2,5-disubstituted-1,3,4-oxadiazoles // J. Chem. Technol. Biotechnol. 1996. Vol. 67. P. 124-130. http://dx.doi.org/10.1002/(SICI)10974660(199610)67:2<124::AID-JCTB528>3.0.CO;2-G

12. Wheeler R. E., King W. F. U. S. Patent 4213973, 1980.

13. Mickevičius V., Intaitė V., Voskienė A., Kantminienė K., Stasevych M., Komarovska-Porokhnyavets O., Novikov V. Synthesis and biological activity of mono- and disubstituted 1,2,4-triazole derivatives // Heterocycles. 2010. Vol. 81. N 3. P. 649-658. http://dx.doi.org/10.3987/COM-09-11887.

14. Upmanyu N., Kumar S., Kharya M.-D., Shah K., Mishra P. Synthesis and anti-microbial evaluation of some novel 1,2,4-triazole derivatives // Acta Pol. Pharm. - Drug. Res. 2011. Vol. 68. N 2. P. 213-221.

15. Ozkirimli S., Apak T. I., Kiraz M., Yegenoglu Y. Synthesis of new triazolyl- $N, N$-dialkyldithiocarbamates as antifungal agents // Arch. Pharm. Res. 2005. Vol. 28. N 11. P. 1213-1218. http://dx.doi.org/10.1007/BF02978200

16. Popiolek L., Kosikowska U., Mazur L., Dobosz M., Malm A. Synthesis and antimicrobial evaluation of some novel 1,2,4-triazole and 1,3,4-thiadiazole derivatives // Med. Chem. Res. 2013. Vol 22. N 7. P. 3134-3147. http://dx.doi.org/10.1007/s00044-012-0302-9.

17. Holla B. S., Veerendra B., Shivananda M. K., Poojary B. Synthesis characterization and anticancer activity studies on some mannich bases derived from 1,2,4-triazoles // Eur. J. Med. Chem. 2003. Vol. 38. P. 759-767. http://dx.doi.org/10.1016/S0223-5234(03)00128-4

18. Kane J. M., Dudley M. W., Sorensen S. M., Miller F. P. 2,4-Dihydro-3H-1,2,4-triazole-3-thiones as potential antidepressant agents // J. Med. Chem. 1988. Vol. 31. P. 1253-1258. http://dx.doi.org/10.1021/jm00401a031

19. Lai C. C., Teng L. J., Hsueh P. R., Yuan A., Tsai K. C., Tang J. L., Tien H. F. Clinical and microbiological characteristics of Rhizobium radiobacter infections // Clin. Infect. Dis. 2004. Vol. 38. P. 149-153. http://dx.doi.org/10.1086/380463

20. Büttner D., Noël L., Thieme F., Bonas U. Genomic approaches in Xanthomonas campestris pv. vesicatoria allow fishing for virulence genes // J. Biotechnol. 2003.
Vol. 106. P. 203-214.

http://dx.doi.org/10.1016/j.jbiotec.2003.07.012

21. Massomo S. M. S., Nielsen H., Mabagala R. B., Mansfeld-Giese K., Hockenhull J., Mortensen C. N. Identification and characterisation of Xanthomonas campestris pv. campestris strains from Tanzania by pathogenicity tests, Biolog, rep-PCR and fatty acid methyl ester analysis // Eur. J. Plant. Pathol. 2003. Vol. 109. P. 775-789. http://dx.doi.org/10.1023/A:1026194402701

22. Madhu L. N., Suchetha Kumari N., Sarojini B. K. In vitro and in vivo antioxidant property of sulphydryl group containing 1,2,4 triazole derivative // Drug Invention Today. 2011. Vol. 3. P. 297-300.

23. Mickevičius V., Vaickelionienė R., Jonuškienė I., Mikulskienė G., Kantminienė K. Synthesis and properties of 1-(3-(fluoromethyl and trifluoromethyl)phenyl)-5oxopyrrolidine-3-carboxylic acid derivatives // Monatsh. Chem. 2009. Vol. 140. P. 1513-1522. http://dx.doi.org/10.1007/s00706-009-0201-z

24. Brokaite K., Mickevicius V., Mikulskiene G. Synthesis and structural investigation of some 1,4-disubstituted-2pyrrolidinones // ARKIVOC. 2006. Vol. ii. P. 61-67.

25. Mickevičius V., Voskienė A., Jonuškienė I., Kolosej R., Šiugždaitė J., Venskutonis P. R., Kazernavičiūtė R., Brazienė Z., Jakienė E. Synthesis and biological activity of 3-[phenyl(1,3-thiazol-2-yl)amino]propanoic acids and their derivatives // Molecules. 2013. Vol. 18. P. 15000-15018. http://dx.doi.org/10.3390/molecules 181215000

26. Mickevičius V., Vaickelionienė R., Sapijanskaitė B. Synthesis of substituted 1,3,4-oxadiazole derivatives // Chem. Heterocycl. Compd. 2009. Vol. 45. P. 215-218. http://dx.doi.org/10.1007/s10593-009-0252-4

27. Chhajed M., Shrivastava A. K., Taile V. Synthesis of 5arylidine amino-1,3,4-thiadiazol-2-[(N-substituted benzyol)]sulphonamides endowed with potent antioxidants and anticancer activity induces growth inhibition in HEK293, BT474 and NCI-H226 cells // Med Chem Res. 2014. Vol. 23. P. 3049-3064.

http://dx.doi.org/10.1007/s00044-013-0890-z 
K. Anusevičius, E. Slaninaitè, I. Jonuškienè,

B. Sapijanskaitė, R. Vaickelionienè, V. Mickevičius

4-PAKEISTŲJŲ 1-(4-METOKSIFENIL)PIROLIDIN-2-

ONŲ SINTEZĖ IR ANTIBAKTERINIS BEI

ANTIOKSIDACINIS AKTYVUMAS

\section{S a n t r a u k a}

Pasinaudojus 1-(4-metoksifenil)-5-oksopirolidin-3karbohidrazido kondensacijos reakcijomis arba modifikuojant gautuosius produktus susintetinta daug 4-pakeistujų 1-(4metoksifenil)pirolidin-2-onų, turinčiu azolo, diazolo, oksadiazolo, tiadiazolo, triazolo fragmentus. Šių struktūrų susidarymas patvirtintas remiantis analitinių ir spektroskopiniu tyrimų duomenimis. Ištirtas naujų junginių antibakterinis aktyvumas prieš Rhizobium radiobacter, Xanthomonas campestris ir Escherichia coli bakteriju padermes. Tik dvi heterociklinès sistemos - 5-tiokso-4,5-dihidro-1,3,4oksadiazolas ir $[1,2,4]$ triazol $[3,4-b][1,3,4]$ tiadiazinas pasižymèjo vidutiniu poveikiu prieš minètus mikroorganizmus. Ištyrus keleto susintetintu junginių antioksidacines savybes, nustatyta, kad labiausiai oksidacinius procesus slopino 1-(4metoksifenil)-4-(4,5-dihidro-5-tiokso-1,3,4-oksadiazol-2-

il)pirolidin-2-onas, deguonies atomą 1,3,4-oksadiazolo žiede pakeitus azoto atomu, junginio antioksidacinis poveikis sumažejo. 